\title{
Treatment of Diabetic Macular Oedema - Clinical Trial Findings and Real-world Outcomes Data
}

\author{
Albert J Augustin \\ Department of Ophthalmology, Städtisches Klinikum Karlsruhe, Karlsruhe, Germany
}

DOI: http://doi.org/10.17925/EOR.2016.10.01.31

\begin{abstract}
In recent years, several intravitreal drug applications have become available for the treatment of diabetic macular oedema (DME). This review aims to summarise and compare available results. Based on a PubMed search, appropriate studies or reviews were evaluated. Clinical trial data suggest that the intravitreal administration of both vascular endothelial growth factor (VEGF) inhibitors and corticosteroids is effective and that overall outcomes are comparable between treatments. Sustained delivery of corticosteroids presents a less treatment-intensive alternative, potentially reducing side effects and enhancing compliance. Compared with clinical development data, recent findings from clinical practice suggest a lesser, more flexible injection frequency in VEGF inhibitors is associated with less pronounced efficacy results. In contrast, corticosteroids treatment frequency seems to correspond with pivotal trial results, reporting equal (or slightly higher or lower) treatment schedules, resulting in similar or higher efficacy values. Safety issues differ between drug classes. Corticosteroid side effects are essentially of local nature and mainly consist of intraocular pressure increases and progression of cataract, limiting their use to pseudophakic patients or those for whom alternative treatments are not effective or are inappropriate. Anti-VEGF treatment is also associated with ocular side effects, but also with reports on systemic side effects, such myocardial infarctions or vascular thromboembolic events. More long-term clinical practice data need to be generated to inform about effectiveness and safety of available therapies in specific patient populations.
\end{abstract}

\section{Keywords}

Aflibercept, bevacizumab, biodegradable, corticosteroids, dexamethasone, diabetic macular oedema, fluocinolone, intravitreal, non-biodegradable, ranibizumab, sustained drug-delivery systems, vascular endothelial growth factor (VEGF) inhibitors

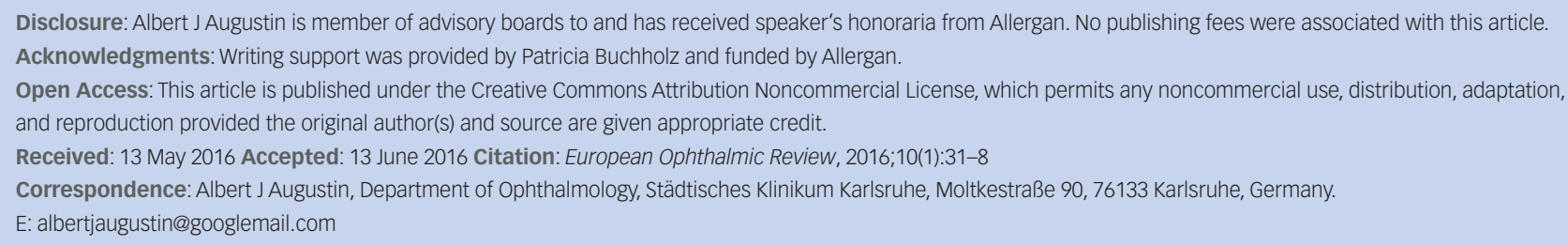

Diabetic macular oedema (DME) is a severe ocular complication of diabetic retinopathy (DR). ${ }^{1}$ Despite the fact that significant advances are being made in early diagnosis and treatment of patients, numbers of patients likely to develop vision loss or blindness due to DR and DME are expected to rise in parallel to the incidence of diabetes. Estimates have projected that, by 2050, there will be in excess of 50 million diabetics in the US, half of whom are projected to develop DR. ${ }^{2-4}$

The treatment of DME has evolved dramatically over the past decade. While laser therapy presented the standard of care for many years, ${ }^{5}$ recent times have seen the introduction of several new therapeutic approaches. All of these therapies have in common that they are applied intravitreally. For many of these treatments, initial data from pivotal clinical trial programmes are now being supplemented by clinical practice data. This article aims to identify and review the available data to determine how newer therapies perform in real-world practice compared with the initial clinical trial setting.

A search of the US National Library of Medicine, National Institutes of Health (http://www.ncbi.nih.gov/pubmed) was performed for the time period between June 2009 and March 2016, based on the following search terms: "diabetic macular edema" and "outcomes" and the respective active compound ("aflibercept", "bevacizumab", "dexamethasone", "fluocinolone" or "ranibizumab"). Publications of individual study reports as well as review articles were included to generate a balanced review of the current state of play.

The two fundamental therapeutic groups now available for the indication of DME are vascular endothelial growth factor (VEGF) inhibitors and corticosteroids.

\section{Intravitreal anti-vascular endothelial growth factor therapies}

Licensed VEGF inhibitors include ranibizumab and aflibercept. Additionally, bevacizumab is used as an off-label option in clinical practice.

\section{Ranibizumab and bevacizumab}

Key information on study set up as well as study results for ranibizumab and bevacizumab are listed in Table 1. 


\section{Table 1: Anti-VEGF compounds - summary of results from clinical trials}

\begin{tabular}{|c|c|}
\hline Trial & Interventions \\
\hline $\begin{array}{l}\text { Brown et al. } 2013 \\
\text { (RISE) }\end{array}$ & $\begin{array}{l}\text { Ran } 0.5 \text { mg, (Ran } 0.3 \mathrm{mg} \text { ) versus sham/Ran } \\
0.5 \mathrm{mg} \text { in } 377 \text { patients }\end{array}$ \\
\hline Prospective & \\
\hline
\end{tabular}

Brown et al. 2013 Ran 0.5 mg, (Ran $0.3 \mathrm{mg}$ ) versus sham/Ran

(RIDE) $0.5 \mathrm{mg}$ in 382 patients

Prospective

\section{Efficacy Outcomes VA (CRT)}

BCVA gain of more than 15 letters after 36 months:

$41.6 \%$ versus $22 \%(p=0.0002)$

Mean BCVA gain of 11 (SD 12.9) letters in Ran

$0.5 \mathrm{mg}$ versus sham 4.3 (SD 14.9)

Reduction in CFT: $269.1 \mu \mathrm{m}$ versus $200.1 \mu \mathrm{m}$

BCVA gain of more than 15 letters after 36 months:

$40.2 \%$ versus $19.2 \%$

Mean BCVA gain of 11.4 (SD16.3) letters in Ran 0.5

mg versus. sham 4.7 (SD 13.3)

Reduction in CFT: $261 \mu \mathrm{m}$ versus $213 \mu \mathrm{m}$

Delayed treatment in patients receiving sham did not

lead to same extent of vision gain

\section{Safety}

IOP increase Ran 0.5 mg versus sham:

$14 \%$ versus $2 \%$

APTC events RISE AND RIDE:

Ran 0.5 mg: 10.4\%;

Sham/Ran $0.5 \mathrm{mg} 7.2 \%$

IOP increase Ran 0.5 mg versus. sham: $18.5 \%$ versus $11 \%$

APTC events RISE and RISE:

see above
Massin et al. 2010 Ran 0.5 mg, (Ran 0.3 mg) versus sham in 382

(RESOLVE)

Prospective

Mitchell et al. 2011 Ran 0.5 mg versus Ran 0.5 mg plus laser

(RESTORE)

Prospective

Schmidt-Erfurth et Individualised Ran $0.5 \mathrm{mg}$

al. 2014 (RESTORE in 208 patients

extension study)
BCVA (EDTRS) gain at 12 months:

IOP increase Ran $0.5 \mathrm{mg}$ versus sham:

8.8 letters ( $p<0.001$ versus sham) versus 11.8 versus $29 \%$ versus $2 \%$

-1.4 letters

BCVA (EDTRS) gain at 12 months:

IOP increase Ran 0.5 mg versus Ran 0.5

6.1 letters ( $p<0.001$ versus laser) versus. 5.9 ( $p<0.001 \mathrm{mg}$ plus laser: $<1 \%$ versus $<1 \%$

versus laser) versus 0.8 letters ATE

CRT reduction 128 versus 119 versus $61 \mu \mathrm{m}$

$5 \%$ versus $<1 \%$

BCVA (EDTRS) gain fom baseline at month 36: $\quad$ Cataract incidence: $16.3 \%$

Prior Ran 0.5 group: 8 letters

Prior Ran 0.5 mg plus laser: 6.7 letters

Prior laser only: 6 letters

Mean number of injections: 6.5 from months $12-36$

CRT reduction:

Prior Ran 0.5 group: $142.1 \mu \mathrm{m}$

Prior Ran $0.5 \mathrm{mg}$ plus laser: $145.9 \mu \mathrm{m}$

Prior laser only: $142.7 \mu \mathrm{m}$

Ohji et al. 2012 Ran $0.5 \mathrm{mg}$ versus Ran $0.5 \mathrm{mg}$ plus laser versus

(REVEAL) laser in 396 patients

Prospective

Googe et al. 2011 Sham versuss Ran 0.5 mg versus Triamcinolone

DRCR.net
$4 \mathrm{mg}$

Focal/grid laser for DME

Prompt PRP for DR

in 145 eyes
5.9 letters $(p<0.001)$ versus $5.7(p<0.001)$ versus 1.4 letters

Mean change in BCVA from baseline at 14 weeks:

Sham group: $-4 \pm 14$

Ran 0.5 group: $1 \pm 11(p<0.001)$

Triam 4 mg group: $2 \pm 11(p<0.001)$
56 weeks safety outcomes:

cerebrovascular/cardiovascular events:

Sham: $4 \%$

Ran 0.5 mg: 7\%

Triamcinolone: $3 \%$
Elman et al. 2015 Ran $0.5 \mathrm{mg}$ plus prompt laser versus Ran $0.5 \mathrm{mg}$ The mean change in VA from baseline through

DRCR.net plus deferred laser in $(163+150)$ patients

Prospective $\quad$ for $\leq 24$ weeks in DME involving central

the 5-year visit: 7.2 letters versus 9.8 letters $(p=0.09)$

Improvement of $\geq 10$ letters in $46 \%$ versus $58 \%$,

macula

Improvement of $>15$ letters in $27 \%$ versus $38 \%$

Bressler et al. 2016 Ran $0.5 \mathrm{mg}$ plus deferred laser versus Ran $0.5 \mathrm{mgMean}$ change at 5 years in VA $( \pm$ SD):

DRCR.net $\quad$ plus prompt laser versus laser/very deferred Ran RL(D): $10 \pm 13.8$

(Protocol I) $\quad 0.5$ mg versus triamcinolone plus laser/very $\quad$ RL(P): $10 \pm 13.5$

Prospective deferred Ran $0.5 \mathrm{mg}$ at total of 828 eyes $\quad L(D R): 5 \pm 14$

TL(DR): $7 \pm 14$

Menchini et al. 2015 Ran 0.5 mg, laser as needed in 515 patients

(PRIDE) (unilateral and bilateral treatment); $10 \%$ naïve patients

Wells et al. 2016 Ran 0.3 mg, Bev 1.25 mg or AFL 2.0 mg

DRCR.net Laser as needed

Mean VA gain in decimal scores $( \pm$ SD) at month 5 :

Unilateral: $1.5 \pm 2.38$

Bilateral: $1.22 \pm 1.67$

Mean VA gain at 2 years:

Ran 12.3, Bev 10.0,

AFL12.8

VA gains in patients with VA 20/32 to 20/40:

Ran 8.6, Bev 6.8, Afl 7.8

Michaelidis et al. Bev $1.25 \mathrm{mg}$ versus laser

Mean gain in BCVA at 24 months:

Bev: 8.6 letters

No significant ocular events

Laser: -0.5 letters

Patients gaining BCVA of $\geq 10$ EDTRS letters at 24

month: Bev: $49 \%$ ( $p<0.001$ versus laser), laser: $7 \%$ 
Table 1: cont.

$\begin{array}{llll}\text { Trial } & \text { Interventions } & \text { Efficacy Outcomes VA (CRT) } & \text { Safety } \\ \text { Lam et al. } 2009 & \text { Bev 1.25 mg versus Bev 2.5 mg in } 52 \text { patients } & \text { Mean BCVA gain in EDTRS letters at month 6: } & \text { Bev 1.25: } 5.5 \text { letters } \\ & & \text { Bev 25: 6.5 letters }\end{array}$

Do et al. 2012 (DA AFL 0.5q4, AFL 2q4 versus AFL 2q8 versus AFL Mean change in BCVA (EDTRS letters) at week 52: Increased IOP in 11\% of patients only 2

VINCI) PRN, aser in 221 patients $\quad 11.0$ versus 13.1 versus 9.7 versus 12.0 versus $-1.3 \%$ patients had an increase of $>10$ mmHg

of eyes with a BCVA gains of $>15$ letters: 40.9 versus

45.5 versus 23.8

versus 42.2 versuss 11.4

Mean reduction in CRT $(\mu \mathrm{m}):-165.4$ versus 227.4

versus 187.7 versus 180.3 versus -58.4

Brown et al. 2016 AFL 2q4 versus AFL 2 q8 versus laser in 406

Mean change in BCVA (EDTRS letters) at month 12:

VIVID patients

10.5 versus 10.7 versus 1.2

Mean BCVA gain at 100 weeks: 11.4, 9.4 and

Most frequent serious ocular adverse

0.7 letters $(p<0.0001)$

Proportion of eyes with $>15$ letter gain at week

100: $38.2,31.1$ and $12.1 \%(p \leq 0.0001)$

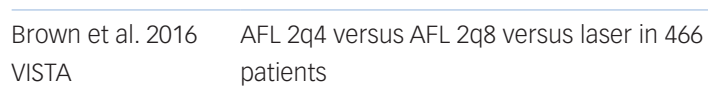

Mean change in BCVA (EDTRS letters) at month 12:

12.5 versus 10.7 versus 0.2

Mean BCVA gain at 100 weeks: 11.5, 11.1 and

0.9 letters $(p<0.0001)$

Proportion of eyes with $>15$ letter gain at week

100: 38.3, 33.1 and $13.0 \%(p<0.0001)$

Rahimy et al. 2016 AFL in 50 eyes previously treated with Mean change of VA (logMAR): $-0.05 \pm 0.22(p=0.12)$

Ran or Bev Mean decrease in CMT of $112 \pm 141 \mu \mathrm{m}(\mathrm{p}<0.0001)$

AES = adverse events; $A T E=$ arterial thrombo-embolic events; $A P T C=$ Anti-Platelet Trialists ${ }^{\prime}$ Collaboration; $B C V A=$ best corrected visual acuity; Bev $=$ bevacizumab; $C F T=$ central foveal thickness; $C R T=$ central retinal thickness; $D M E=$ diabetic macular oedema; $D R=$ diabetic retinopathy; $E D T R S=$ early treatment diabetic retinopathy study; IOP = intraocular pressure; $P R N=$ pro re nata; $R a n=$ ranibizumab; $V A=$ visual acuity.

Ranibizumab was initially investigated in DME patients in a phase I/ II open-label evaluation (READ-2 study) as well as a phase II trial (RESOLVE). ${ }^{6}$ Several phase III studies in DME followed. The RISE and RIDE studies were two parallel studies which ran for a time period of 36 months. Gains in visual acuity (VA) and improvement in retinal anatomy was sustained over three years. The proportions of patients who gained at least 15 letters from baseline in the sham/0.5 mg, $0.3 \mathrm{mg}$ and $0.5 \mathrm{mg}$ ranibizumab groups were $19.2 \%, 36.8 \%$ and $40.2 \%$, respectively, in RIDE and $22.0 \%, 51.2 \%$ and $41.6 \%$, respectively, in RISE.?

REVEAL and RESTORE compared ranibizumab alone to laser alone or to combination treatment. Notably, the addition of laser did not confer additional benefit. ${ }^{8}$ The RESTORE three-year outcomes study demonstrated that ranibizumab was effective in improving and maintaining best corrected VA (BCVA), central retinal thickness (CRT) outcomes with a progressively declining number of injections per year (mean of $<3$ injections). ${ }^{9}$

Real-world clinical practice data are also available from open-label extensions of the original clinical trials, as well as from post-licensing studies, giving physicians the opportunity to inject the product on an as-needed basis (pro re nata [PRN]). Data from the extension of RESTORE demonstrated that improvements in BCVA and CRT were also maintained at year three, with patients requiring fewer injections over this time.?

The Diabetic Retinopathy Clinical Research Network (DRCR.net) study demonstrated that the addition of one intravitreal triamcinolone or two ranibizumab injections in eyes receiving focal/grid laser for DME and panretinal photocoagulation (PRP) is associated with better VA and decreased macular oedema by 14 weeks. ${ }^{10}$ Another DRCR.net study, performed in patients with decreased VA and DME involving the fovea over five years, reported that patients treated with ranibizumab plus prompt laser or ranibizumab plus deferred laser maintained visual gains from year 1 to 5 , requiring less treatment after year 3. Notably, patients from the latter group required more ranibizumab injections. ${ }^{11} \mathrm{~A}$ similar study included two additional patient groups receiving laser-only or triamcinolone plus deferred ranibizumab. Authors concluded that eyes receiving initial ranibizumab treatment are likely to have better long-term vision improvements. ${ }^{12}$ An Italian study provided additional evidence. Use of ranibizumab was well tolerated and improved or maintained VA in $40.2 \%$ to $68.8 \%$ of patients, with no difference between unilateral or bilateral cases. ${ }^{13}$

A recent DRCR.net study compared the effectiveness of aflibercept, ranibizumab or bevacizumab for DME over two years (PROTOCOL T). The median number of injections was 15,16 and 15 , respectively over two years, with lesser injections in year 2. Overall, all three treatments improved VA from baseline. While VA outcomes were similar for eyes with better baseline VA, aflibercept had better outcomes compared with bevacizumab over two years, as well as to ranibizumab over the first year in eyes with worse baseline VA. Higher Anti-Platelet Trialists' Collaboration (APTC) event rates with ranibizumab warrant a continued evaluation in future trials. ${ }^{14}$

Bevacizumab is not licensed for the indication of DME, however, it is used in current medical practice. Several studies have demonstrated the efficacy and safety of bevacizumab in DME. The BOLT study compared 
use of bevacizumab with laser treatment (see Table 1). ${ }^{15}$ Faghihi et al reported a similar injection rate and efficacy for bevacizumab $1.25 \mathrm{mg}$ and bevacizumab $1.25 \mathrm{mg}$ plus a single laser treatment over a period of six months. ${ }^{16}$ In a six-month study in patients with diffuse DME, Lam et al. demonstrated a similar efficacy of two different doses of bevacizumab (1.25 mg and $2.5 \mathrm{mg}$ ). ${ }^{17}$ Additional trials have investigated a combination of bevacizumab $1.25 \mathrm{mg}$ and triamcinolone $2 \mathrm{mg}$. Ahmadieh et al. found that the BCVA for the combination was not significantly better than bevacizumab alone. ${ }^{18}$ Soheilian et al. compared bevacizumab $1.25 \mathrm{mg}$ plus triamcinolone $2 \mathrm{mg}$ versus bevacizumab alone and laser alone. Results at 24 months did not favour any of the groups. Lim et al. demonstrated that treatment with a combination of bevacizumab plus triamcinolone, bevacizumab alone or triamcinolone alone did not yield statistically differences between groups in terms of BCVA and CMT. The ATEMD study also found comparable efficacy in the bevacizumab $1.25 \mathrm{mg}$ plus triamcinolone $4 \mathrm{mg}$ group and each monotherapy alone. The adverse event (AE) profile is comparable to ranibizumab. Studies are not powered to detect small differences in rates of infrequent events. Overall, bevacizumab was well tolerated. ${ }^{8}$

\section{Aflibercept}

Key information on study set up as well as study results for aflibercept are listed in Table 1

A multicentre phase II study evaluated the efficacy and safety of different aflibercept concentrations compared with laser in DME patients. Significant gains in BCVA from baseline achieved at week 24 were maintained or improved at week 52 in all aflibercept groups. ${ }^{19}$

The efficacy and safety of aflibercept $2 \mathrm{mg}$ applied monthly (2q4) or every two months (2q8) was compared with laser treatment in two phase III studies. The authors concluded that, in both studies (VISTA and VIVID), the 52-week anatomical and visual superiority of aflibercept injections over laser treatment were significant and similar at week 52 and through week 100. At week 100, the mean BCVA gain was 11.4, 9.4 and 0.7 letters in VIVID and 11.5, 11.1 and 0.9 letters in VISTA for aflibercept 2q4, aflibercept $2 \mathrm{q} 8$ and laser, respectively. ${ }^{20}$ Real-world outcomes in 50 eyes with persistent DME previously treated with ranibizumab or bevacizumab and then switched to aflibercept were recently reported by Rahimy and colleagues. Conversion to aflibercept resulted in significant anatomic improvements, but only trends towards improved VA and reduction in IOP were observed. ${ }^{21}$

\section{Intravitreal corticosteroid delivery systems Fluocinolone}

Key information on study set up as well as study results for fluocinolone are listed in Table 2.

The long-term efficacy and safety of the fluocinolone acetonide (FAC) non-degradable implant was assessed in patients with persistent DME in spite of one or more laser treatments. Subjects were eligible for laser rescue treatment six weeks after injection. Almost all phakic patients in the FAc implant groups developed cataract. However, their actual visual benefit, as determined after removal of the cataract, was similar to pseudophakic patients in the study. Intraocular pressure (IOP) elevations considered an AE were reported in approximately $35 \%$ of patients receiving FAc $0.2 \mu \mathrm{g} /$ day. ${ }^{22}$ In the active group, $18.7 \%$ of patients received two and $6.3 \%$ three or more implants. Laser treatment was administered in $40 \%$ of patients in the active group. Also $13.4 \%$ of patients from this group received additional off protocol treatments such as intravitreal triamcinolone or anti-VEGF compounds. It was concluded that the FAc $0.2 \mu \mathrm{g} / \mathrm{d}$ implant provided substantial benefit for up to three years and thus would provide an option for patients who do not respond to other therapies. ${ }^{23} \mathrm{~A}$ recent study produced data in six pseudophakic patients with bilateral, chronic DME previously treated with laser and anti-VEGF therapy. The FAc implant in both eyes was a feasible, effective second- or third-line choice for patients with severe bilateral DME, without notable increases in IOP. ${ }^{24}$

\section{Dexamethasone}

Key information on study set up as well as study results for dexamethasone (DEX) are listed in Table 2. The DEX implant contains $700 \mu \mathrm{g}$ DEX in an inactive biodegradable polymer matrix. The latter ultimately degrades to water and carbon dioxide and DEX is released over six months. It is indicated patients who have not respond sufficiently to non-corticosteroid treatment, pseudophakic patients and patients deemed to be unsuitable for non-corticosteroid treatment. Efficacy and safety of DEX biodegradable implant is reported in several phase II and III trials. PLACID was a 52-week, masked, multicentre, randomised, sham-controlled phase $\|$ trial. ${ }^{25}$ CHAMPLAIN was a 26week, open-label trial to assess the safety and efficacy of DEX implant in patients with DME who had had pars plana vitrectomy. Patients with DME and a history of vitrectomy showed a benefit of treatment up to six months after implantation in terms of reduction of macular thickness and increase in BCVA. ${ }^{26}$

The MEAD study, a phase three trial, included a total of 1,048 patients. After the first DEX implant treatment, an additional implant could be administered every six months if the thickness of the oedema increased or persistent oedema was present. Patients could receive up to seven treatments during the trial. A very rapid initial response was demonstrated in BCVA values, maintaining statistical significance up to approximately 15 months. This was followed by a drop in BCVA, coinciding with the development of cataract. A subgroup analysis of the patients that were pseudophakic at baseline (approx. 25\%) showed consistency in BCVA improvement throughout the three-year study period compared to sham. VA decreased between the time of reporting cataract AE and cataract surgery but improved to pre-cataract levels after surgery. ${ }^{27}$ A subgroup analysis of patients previously treated for DME (with laser, anti-VEGF therapies, intravitreal triamcinolone acetonide (IVTA) or a combination of these therapies) showed that the DEX implant significantly improved visual and anatomic outcomes. ${ }^{28}$ The BEVORDEX trial compared efficacy and safety of the DEX implant with bevacizumab. At month 12 the percentage of patients reported with $\geq 10 \log M A R$ letters were 40 in the DEX implant and 41 in the bevacizumab group, while CMT was reduced by $187 \mu \mathrm{m}$ and $122 \mu \mathrm{m}$, respectively. ${ }^{29}$ The VA improvement in both groups was maintained at 24 months, while the CMT reduction in the bevacizumab group caught up to be comparable with the DEX implant group. The injection frequency difference for both groups was less pronounced in year 2, still favouring the DEX implant. ${ }^{30} \mathrm{~A}$ 12-month single-masked, randomised controlled study comparing the efficacy of bevacizumab $1.25 \mathrm{mg}$ with a combination of bevacizumab $1.25 \mathrm{mg}$ and the DEX implant in eyes with persistent ME came to the conclusion that the combination significantly improves VA as well as the morphology of refractory DME, although VA gains were not superior to continued bevacizumab therapy. ${ }^{31}$

Recently, data from use of the DEX implant in clinical practice has also become available. A prospective study compared the efficacy of a single administration of DEX implant with monthly intravitreal injections 
Table 2: Corticosteroids - summary of results from clinical trials and real world data

\begin{tabular}{|c|c|c|c|}
\hline Trial & Interventions & Primary Efficacy Outcome & Safety \\
\hline $\begin{array}{l}\text { Campochiaro et al. } \\
2012 \text { (FAME) }\end{array}$ & $\begin{array}{l}\text { FAc implant } 0.2 \mu \mathrm{g} / \text { day ( } 375 \text { patients), } \\
\text { FAc implant } 0.5 \mu \mathrm{g} / \text { day ( } 393 \text { patients), } \\
\text { Sham (185 patients); mean duration } \\
\text { DME in years: FAc } 0.5 \mu \mathrm{g}: 3.5( \pm 2.6) \text {, } \\
\text { Sham: } 3.9 \text { ( } \pm 3.78)\end{array}$ & $\begin{array}{l}\text { BCVA \% patients } \geq 15 \text { EDTRS letters at month } 36 \text { : } \\
\text { FAC } 0.2 \mu \text { g: } 28.7 \text {, (FAC } 0.5 \mu \mathrm{g}: 27.8) \text {, Sham: } 18.9 \text { ( } \mathrm{p}=0.018 \text { ) } \\
\text { Mean change letters from baseline BCVA at month } 36 \text { : } \\
\text { active: } 7.6 \text {; Sham: } 1.8\end{array}$ & $\begin{array}{l}\text { Cataract surgery rate } \\
\text { FAc } 0.2 \mu g: 80 \% \\
\text { Glaucoma surgery rate } \\
\text { FAc } 0.2 \mu \mathrm{g}: 4.8 \%\end{array}$ \\
\hline $\begin{array}{l}\text { Cunha-Vaz et al. } 2014 \\
\text { (FAME) }\end{array}$ & $\begin{array}{l}\text { FAc implant } 0.2 \mu \mathrm{g} / \text { day (209 patients), } \\
\text { Sham ( } 112 \text { patients) } \\
\text { Subgroups chronic patients (>3 years) }\end{array}$ & $\begin{array}{l}\text { BCVA \% chronic patients } \geq 15 \text { EDTRS letters at } \\
\text { month 36: FAc } 0.2 \mu g: 34 \text {, Sham: } 13.4(p<0.001)\end{array}$ & $\begin{array}{l}\text { Cataract surgery rate: } \\
\text { FAc: } 85.1 \% \\
\text { Glaucoma surgery rate: } \\
\text { FAc: } 5.3 \%\end{array}$ \\
\hline $\begin{array}{l}\text { Yang et al. } 2015 \\
\text { (FAME) }\end{array}$ & $\begin{array}{l}\text { FAc implant } 0.2 \mu g / \text { day } \\
\text { Subgroup: phakic ( } 188 \text { patients) versus } \\
\text { pseudophakic ( } 140 \text { patients); median } \\
\text { duration DME: } 1.73 \text { years }\end{array}$ & $\begin{array}{l}\text { BCVA \% patients } \geq 15 \text { EDTRS letters at month } 36 \text { : } \\
\text { Phakic: } 29.3 \\
\text { Pseudophakic: } 35.1\end{array}$ & \\
\hline Elaroud et al. 2016 & $\begin{array}{l}\text { FAc } 0.2 \mu \mathrm{g} / \text { day (six pseudophakic } \\
\text { patients with chronic DME) }\end{array}$ & $\begin{array}{l}\text { Mean change in BCVA } 10 \text { letters ( } \pm 12.2 \text { letters) at } 6 \\
\text { months }\end{array}$ & $\begin{array}{l}\text { Mean IOP was } 16.1 \mathrm{mmHg} \text {; mean } \\
\text { change of } 1.1 \mathrm{mmHg}(\mathrm{SD} \pm 3.6)\end{array}$ \\
\hline $\begin{array}{l}\text { Callanan et al. } 2013 \\
\text { (PLACID) }\end{array}$ & $\begin{array}{l}\text { DEX implant } 0.7 \text { mg plus laser ( } 126 \\
\text { patients), laser ( } 127 \text { patients) in diffuse } \\
\text { DME }\end{array}$ & $\begin{array}{l}\text { Maximum mean VA increase in letters from month } \\
1 \text { to 9: } \\
\text { Dex/laser: } 7.7 \text {; laser: } 2.8 \\
\text { Primary efficacy endpoint of demonstrating benefit } \\
\text { of combination over laser at month } 12 \text { in terms of } \\
\text { proportion of patients gaining } \geq 10 \text { letters was not met }\end{array}$ & $\begin{array}{l}\text { DEX/Laser: IOP elevation in } 20 \% \text { of } \\
\text { patients; IOP rise of } \geq 10 \mathrm{mmHg}: 1 \% \\
\text { patients } \\
\text { Laser: IOP rise of } \geq 10 \mathrm{mmHg} \text { : } 0 \% \\
\text { patients } \\
\text { Cataracts: not reported }\end{array}$ \\
\hline $\begin{array}{l}\text { Boyer et al. } 2011 \\
\text { (CHAMPLAIN) }\end{array}$ & $\begin{array}{l}\text { Open-label efficacy and safety of } \\
\text { DEX } 0.7 \text { mg in patients with pars plana } \\
\text { vitrectomy }\end{array}$ & $\begin{array}{l}\text { Change from baseline at } 26 \text { weeks: reduction of CMT, } \\
\text { Increase of VA }\end{array}$ & $\begin{array}{l}17 \% \text { of patients started taking } \\
\text { IOP-lowering medication during study } \\
\text { period } \\
\text { No patient required laser or surgical } \\
\text { procedure to control IOP, discontinued } \\
\text { study because of elevated IOP }\end{array}$ \\
\hline $\begin{array}{l}\text { Boyer et al. } 2014 \\
\text { (MEAD) }\end{array}$ & $\begin{array}{l}\text { DEX implant } 0.7 \text { mg (351 patients), } \\
\text { DEX implant } 0.35 \text { mg (347 patients), } \\
\text { Sham ( } 350 \text { patients) } \\
\text { Prior treatments in \%: laser (67); } \\
\text { intravitreal steroids (18), anti-VEGF (9) } \\
\text { Mean DME duration: } 24 \text { months }\end{array}$ & $\begin{array}{l}\text { BCVA \% patients } \geq 15 \text { EDTRS letters at month } 36 \text { : } \\
\text { DEX } 0.7 \text { mg: } 22 \text {; Sham: } 12 \text { ( } p<0.018 \text { ) } \\
\text { Mean average reduction over } 36 \text { months versus } \\
\text { baseline: DEX } 0.7 \mathrm{mg}:-111.6 \mu \mathrm{m} \text {; Sham: }-41.9 \mu \mathrm{m} \\
\text { ( } \mathrm{p}<0.001 \text { ) } \\
\text { Similar effect of DEX } 0.7 \mathrm{mg} \text { in subgroups defined by } \\
\text { DME duration }\end{array}$ & $\begin{array}{l}\text { Cataract surgery rate } \\
\text { DEX: } 59 \% \text {, Sham: } 7.2 \% \\
\text { Increased IOP: DEX: } \\
36 \% \text {, Sham } 5 \% \\
\text { IOP lowering medication in DEX: } 42 \% \\
\text { Glaucoma surgery rate: } \\
\text { DEX: } 0.6 \% \text {, Sham } 0 \%\end{array}$ \\
\hline $\begin{array}{l}\text { Augustin et al. } 2015 \\
\text { (MEAD) }\end{array}$ & $\begin{array}{l}\text { DEX implant } 0.7 \mathrm{mg} \text { ( } 247 \text { patients), } \\
\text { Sham ( } 261 \text { patients) } \\
\text { Subgroup: previously treated patients } \\
\text { Mean DME duration in mos: DEX } 0.7 \mathrm{mg} \text { : } \\
27.3 \text { ( } \pm 26.3) \text {; sham: } 31.9( \pm 28.6)\end{array}$ & $\begin{array}{l}\text { BCVA \% patients } \geq 15 \text { EDTRS letters at month } 36 \text { : } \\
\text { DEX } 0.7 \mathrm{mg}: 21.5 \\
\text { Sham: } 11.1(p=0.002)\end{array}$ & $\begin{array}{l}\text { Cataract related events } \\
\text { DEX: } 70.3 \% \text {, Sham: } 20.1 \% \\
\text { IOP related events: } \\
\text { DEX: } 38.1 \% \text {, Sham: } 4.6 \%\end{array}$ \\
\hline $\begin{array}{l}\text { Gillies et al. } 2014 \\
\text { (BEVORDEX) }\end{array}$ & $\begin{array}{l}\text { DEX implant } 0.7 \text { mg ( } 46 \text { eyes), Bev } 1.25 \\
\text { mg (42 eyes) }\end{array}$ & 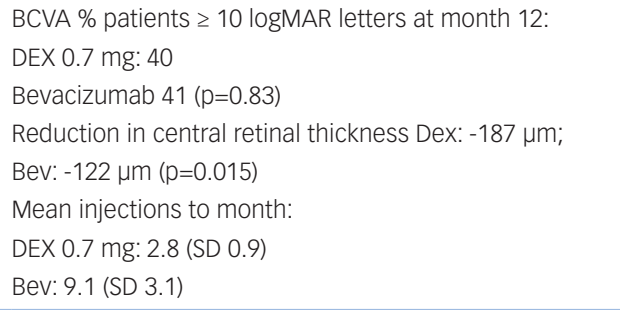 & \\
\hline Fraser-Bell et al. 2016 & $\begin{array}{l}\text { DEX implant } 0.7 \text { mg ( } 46 \text { eyes), Bev } 1.25 \\
\text { mg (42 eyes) }\end{array}$ & $\begin{array}{l}\text { BCVA \% patients } \geq 10 \text { logMAR letters at month 24: } \\
\text { DEX } 0.7 \text { mg: } 43 \\
\text { Bev: } 45 \text { ( } p=0.99 \text { ) } \\
\text { Mean injections from month 12-24: } \\
\text { DEX } 0.7 \text { mg: } 2.2 \text { (SD 1.2) } \\
\text { Bev: } 4.8 \text { (SD 5.1) }\end{array}$ & \\
\hline $\begin{array}{l}\text { Pacella et al. } 2014 \\
\text { Prospective }\end{array}$ & $\begin{array}{l}\text { DEX implant } 0.7 \mathrm{mg} \text { ( } 25 \text { eyes) } \\
\text { Bev } 1.25 \mathrm{mg} \\
(25 \text { eyes); DME duration in mos: } 46.3 \\
( \pm 18.6)\end{array}$ & $\begin{array}{l}\text { Mean VA gain after } 3 \text { months: } \\
8.5 \text { letters versus } 4 \text { letters }\end{array}$ & \\
\hline
\end{tabular}


Table 2: Cont.

$\begin{array}{lll}\text { Trial } & \text { Interventions } & \text { Primary Efficacy Outcome } \\ \text { Maturi et al. } 2015 & \text { DEX implant } 0.7 \mathrm{mg} \text { plus Bev } 1.25 \mathrm{mg} & \text { Mean VA gain from baseline at month } 12: \\ \text { Prospective } & \text { versus Bev } 1.25 \mathrm{mg} \text { alone in } 40 \text { eyes } & \text { Combination group: }+5.4 \text { letters } \\ & & \text { Bev group: } 4.9 \text { letters }(p=0.75) \\ & \text { Mean reduction in CMT: } \\ & \text { Combination group: } 45 \mu \mathrm{m} \\ & \text { Bev group: } 30 \mu \mathrm{m}(\mathrm{p}=0.03)\end{array}$

Shah et al. 2016 Prospective
DEX implant $0.7 \mathrm{mg}$ versus Bev $1.25 \mathrm{mg}$ In 50 eyes

\begin{tabular}{lll}
\hline $\begin{array}{l}\text { Guigou et al. 2015 } \\
\text { Retrospective }\end{array}$ & DEX implant 0.7 mg (74 patients) & Mean VA gain of 8.5 letters and 7.6 letters after \\
& Follow up over a mean of 9.8 months & 2 and 6 months respectively \\
& Patients with a gain of $\geq 15$ letters at month 6: 27\% \\
& Patients with a normal CRT at month 6:34.4\%
\end{tabular}

Escobar-Barranco et DEX implant $0.7 \mathrm{mg}$ (40 refractory and al. $2015 \quad 30$ naïve patients)

Prospective Laser use as needed

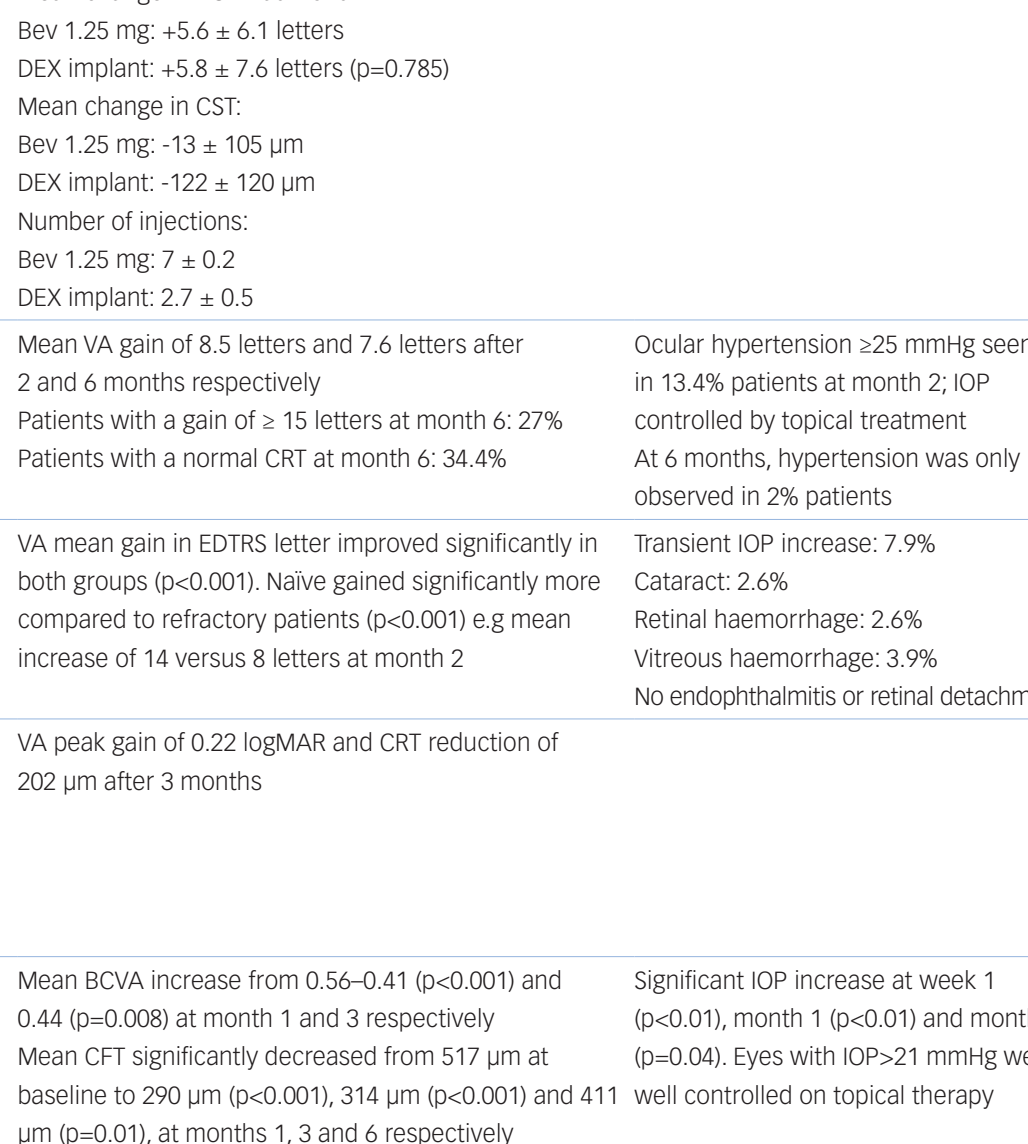

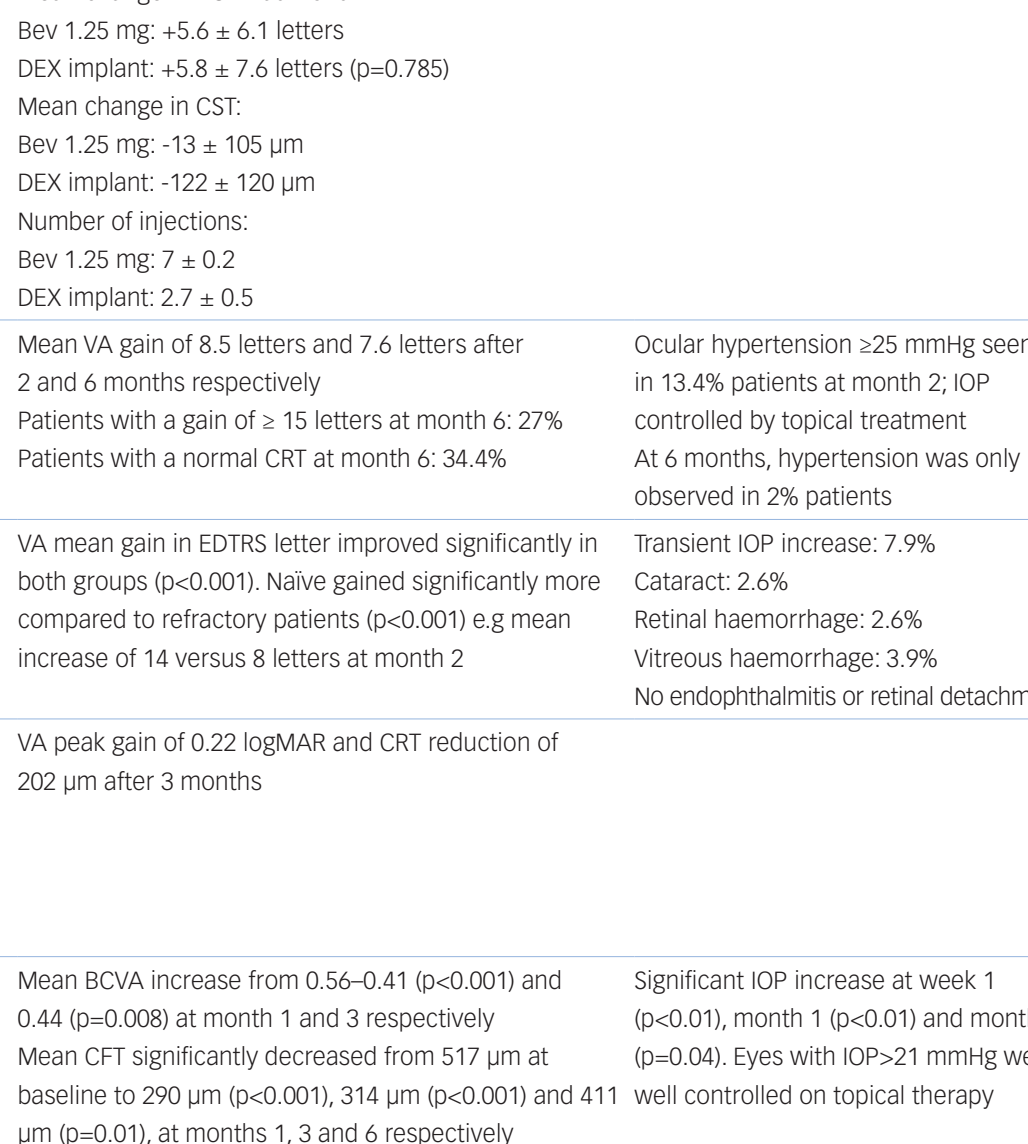

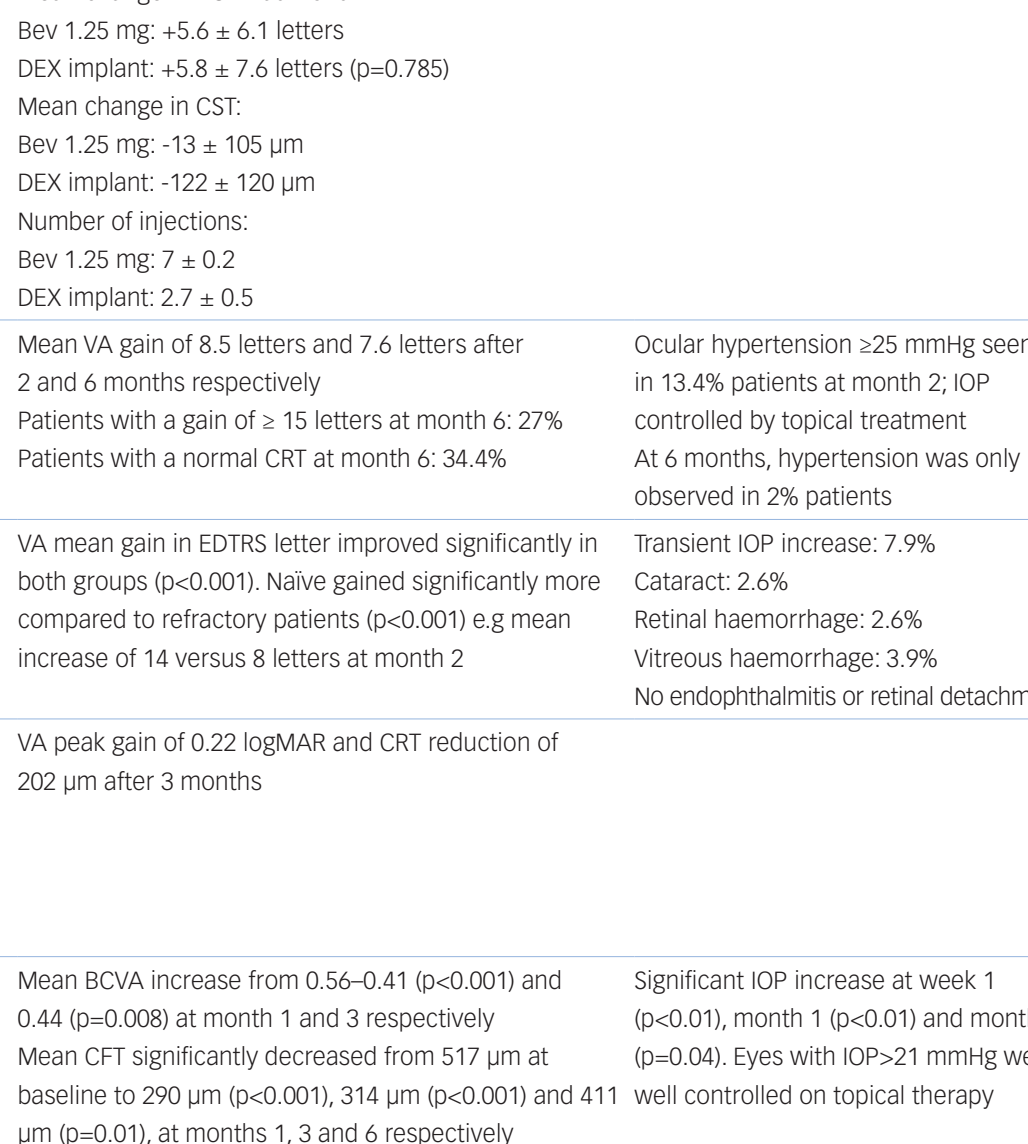

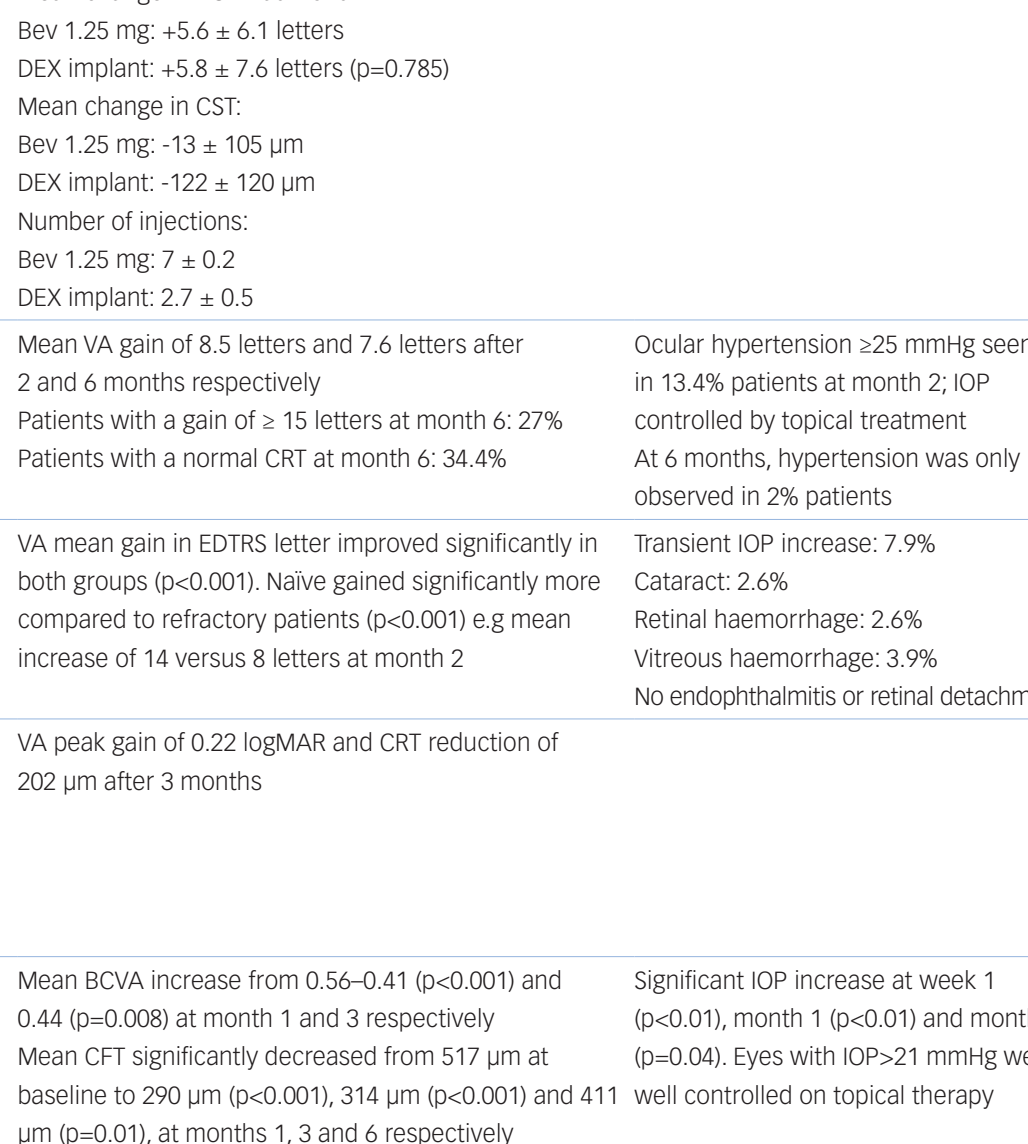

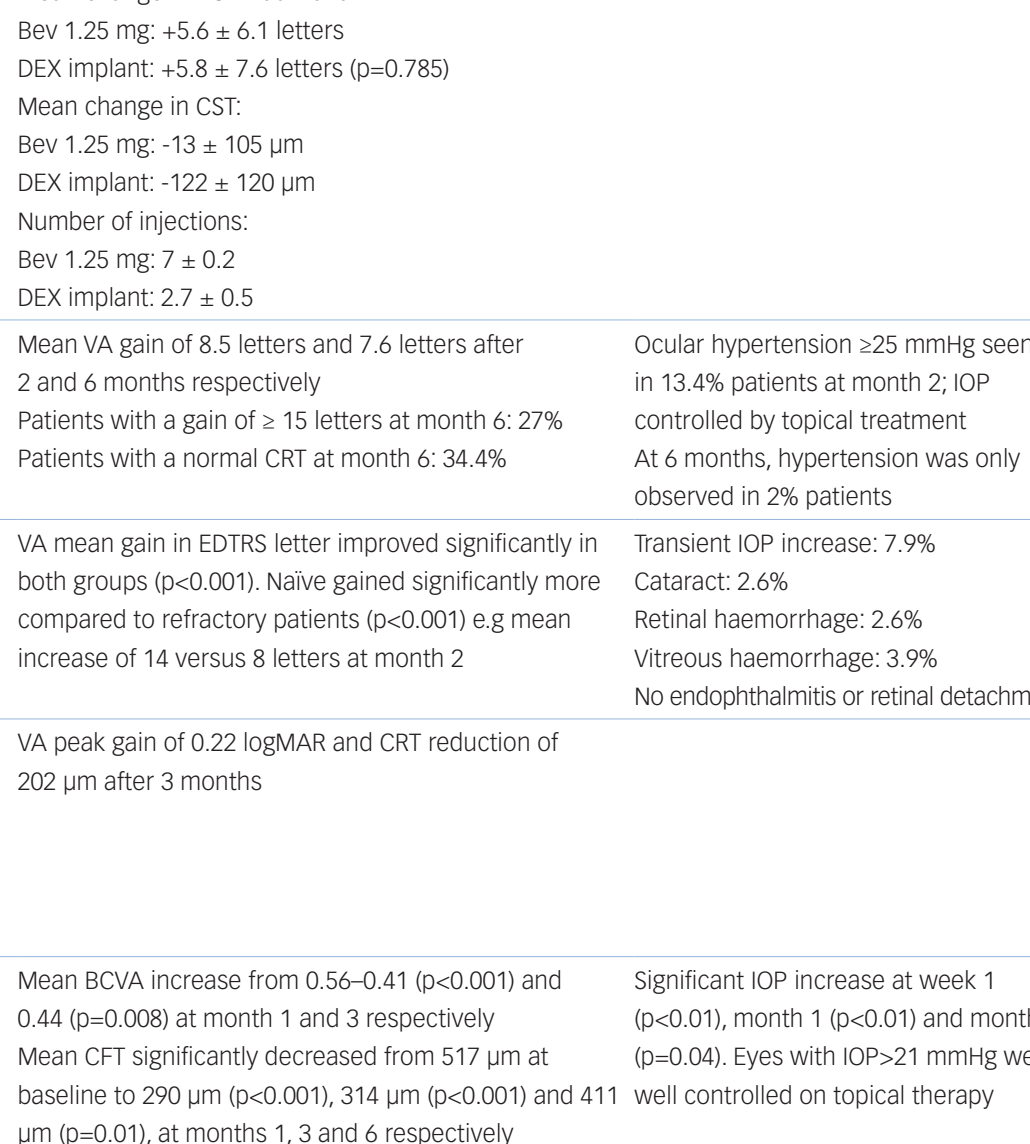

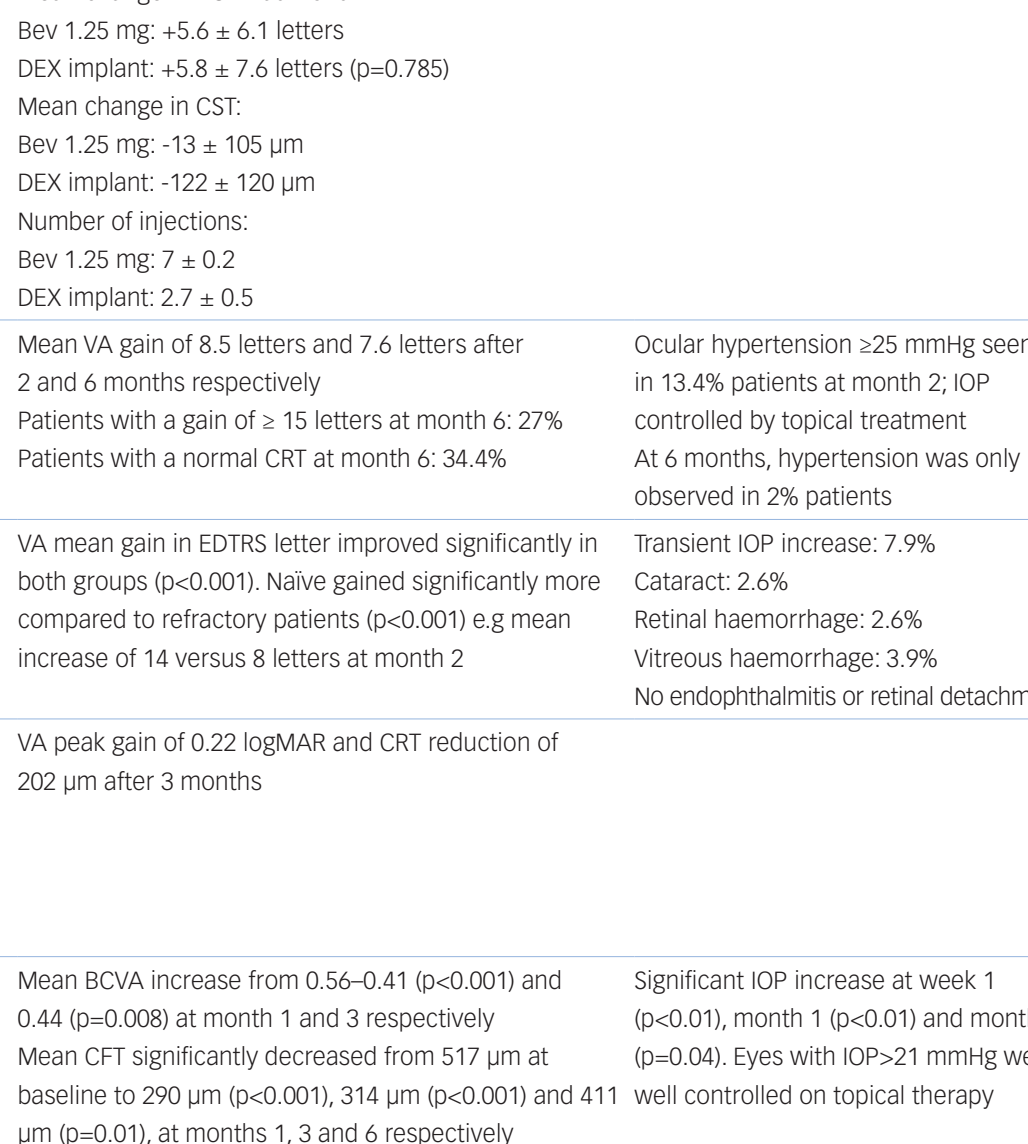

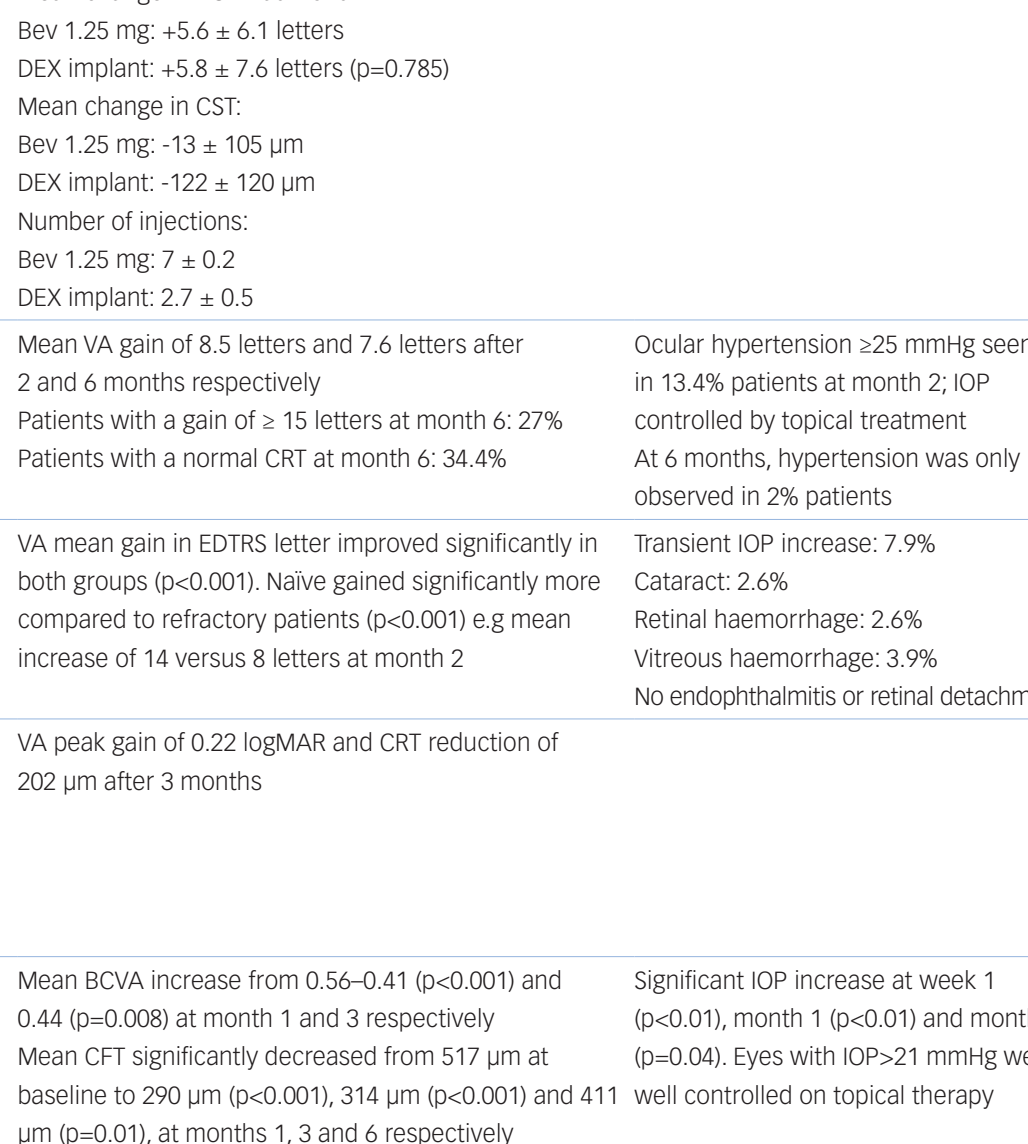

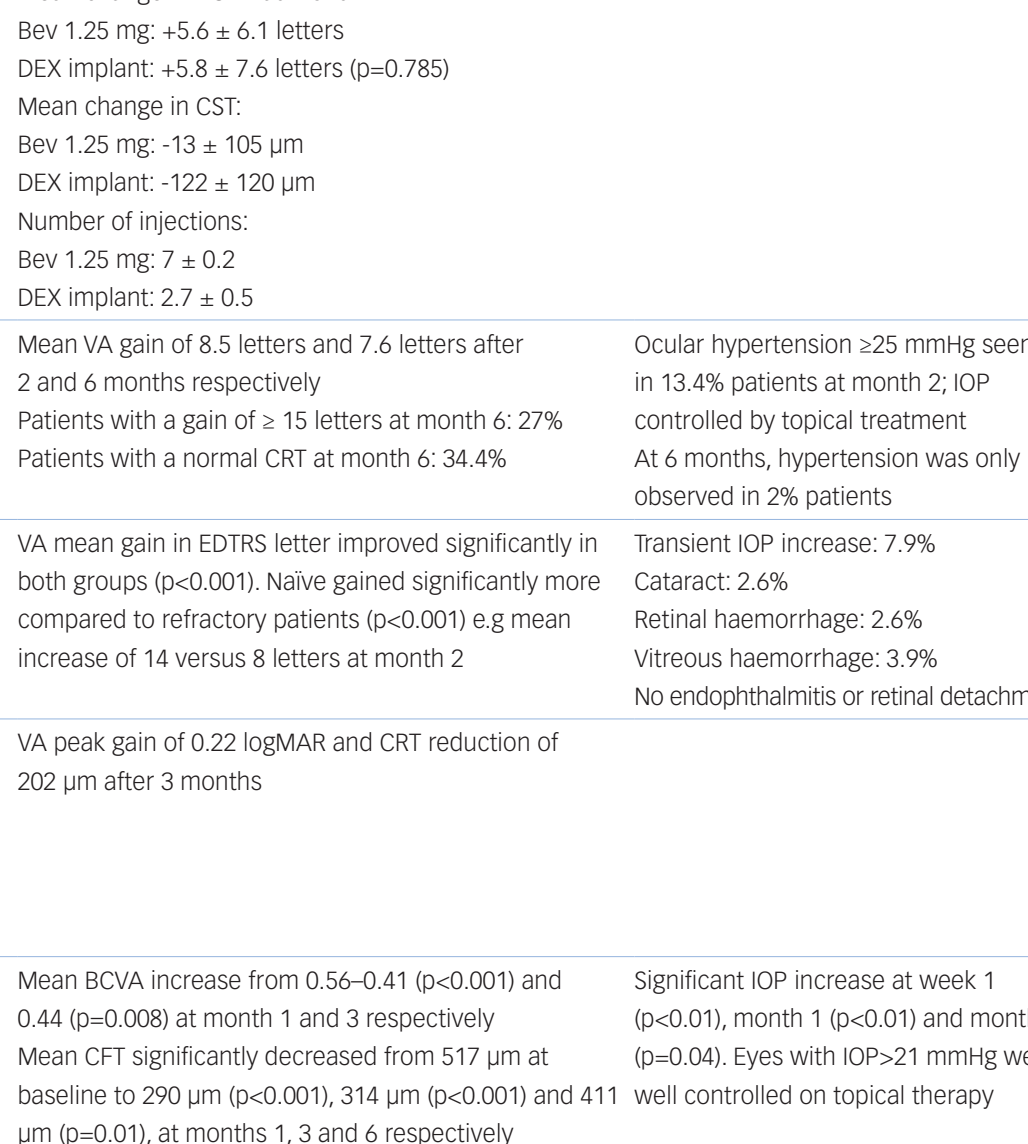

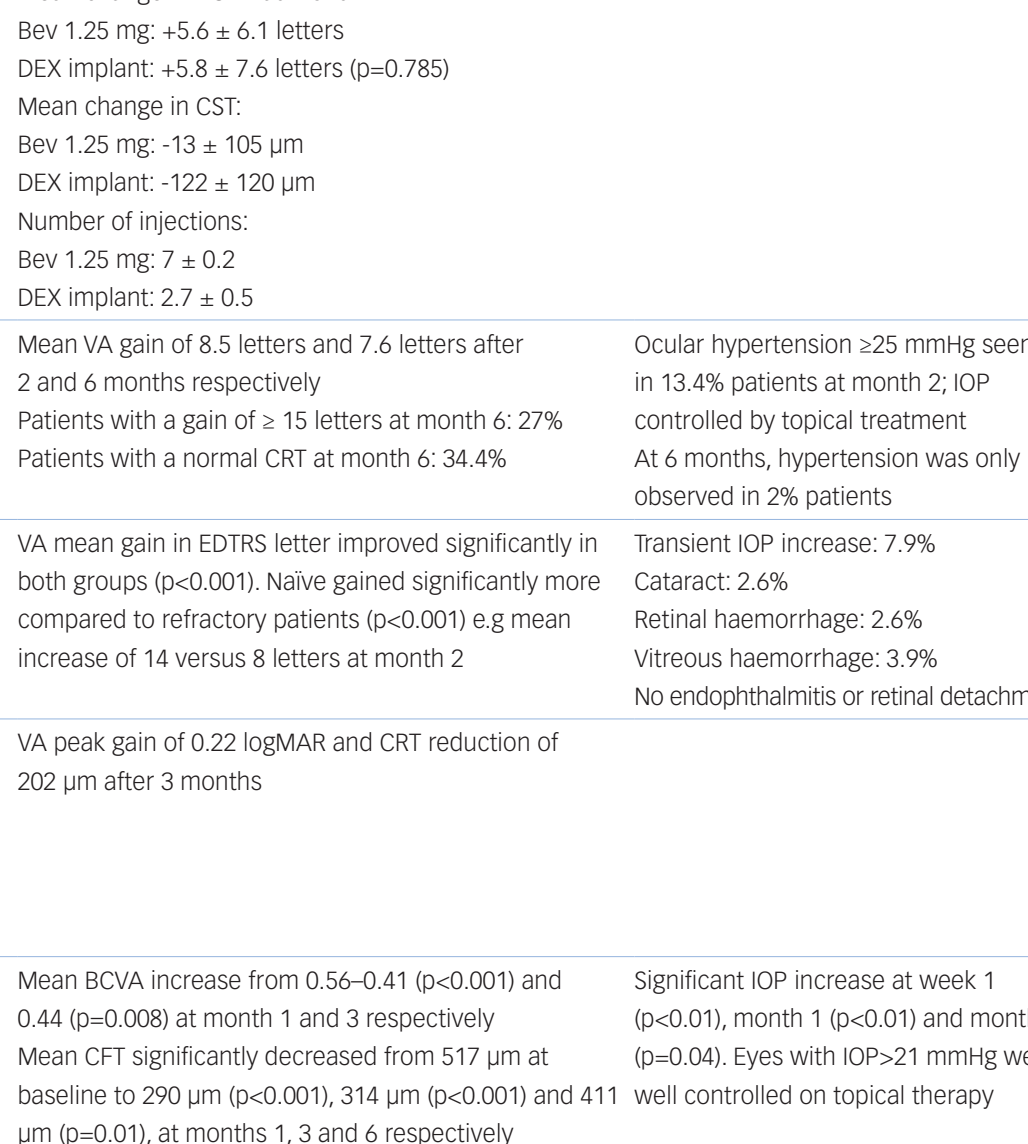

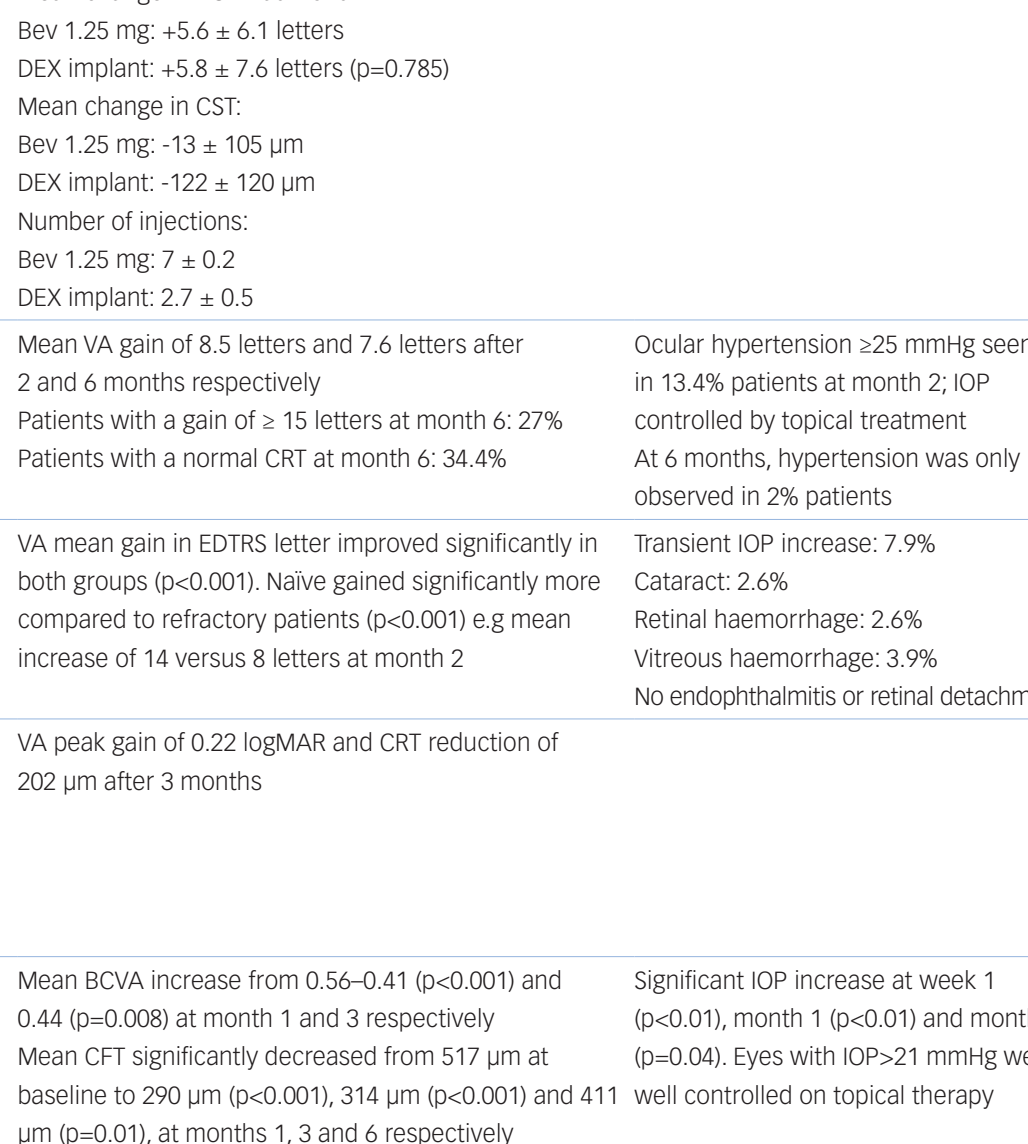

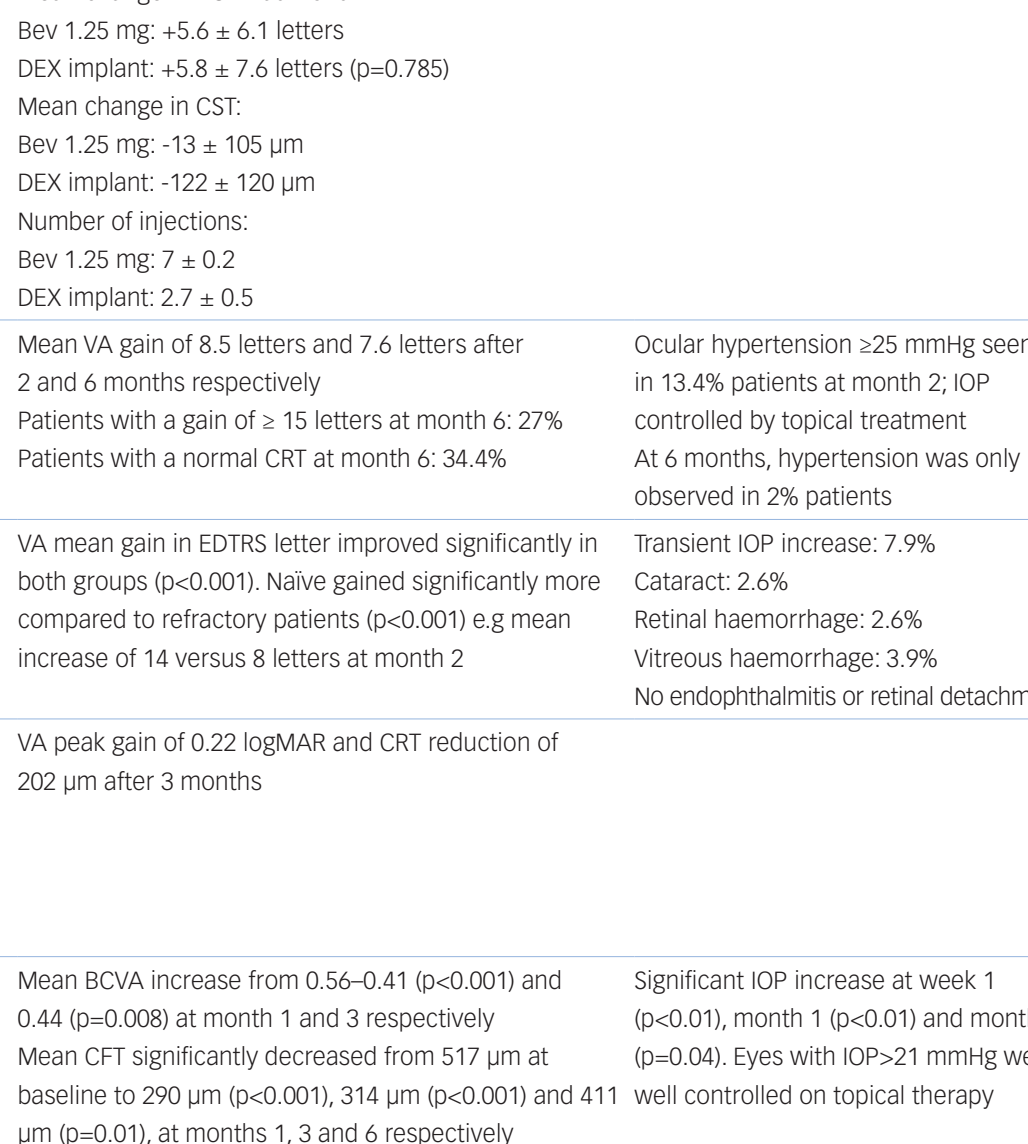

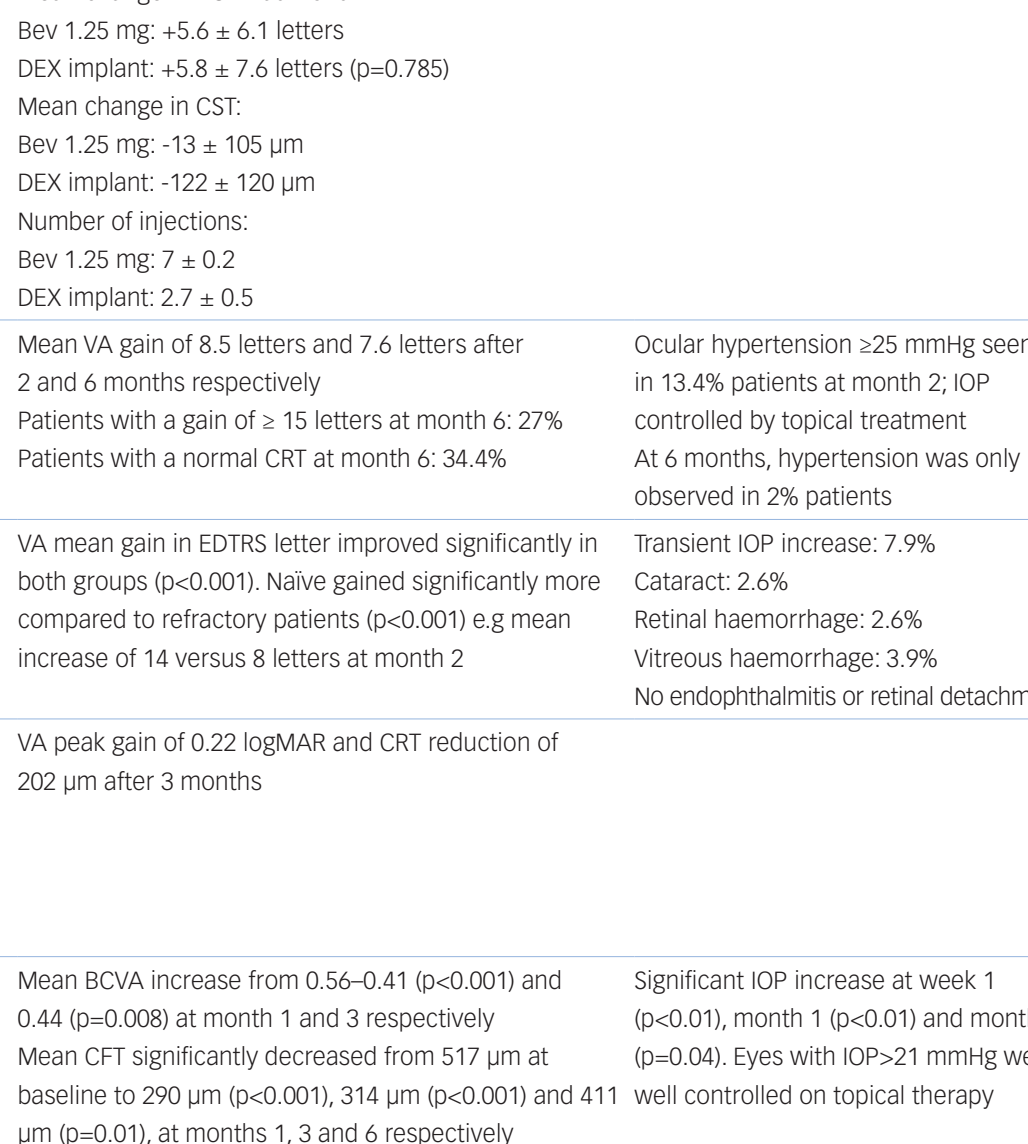

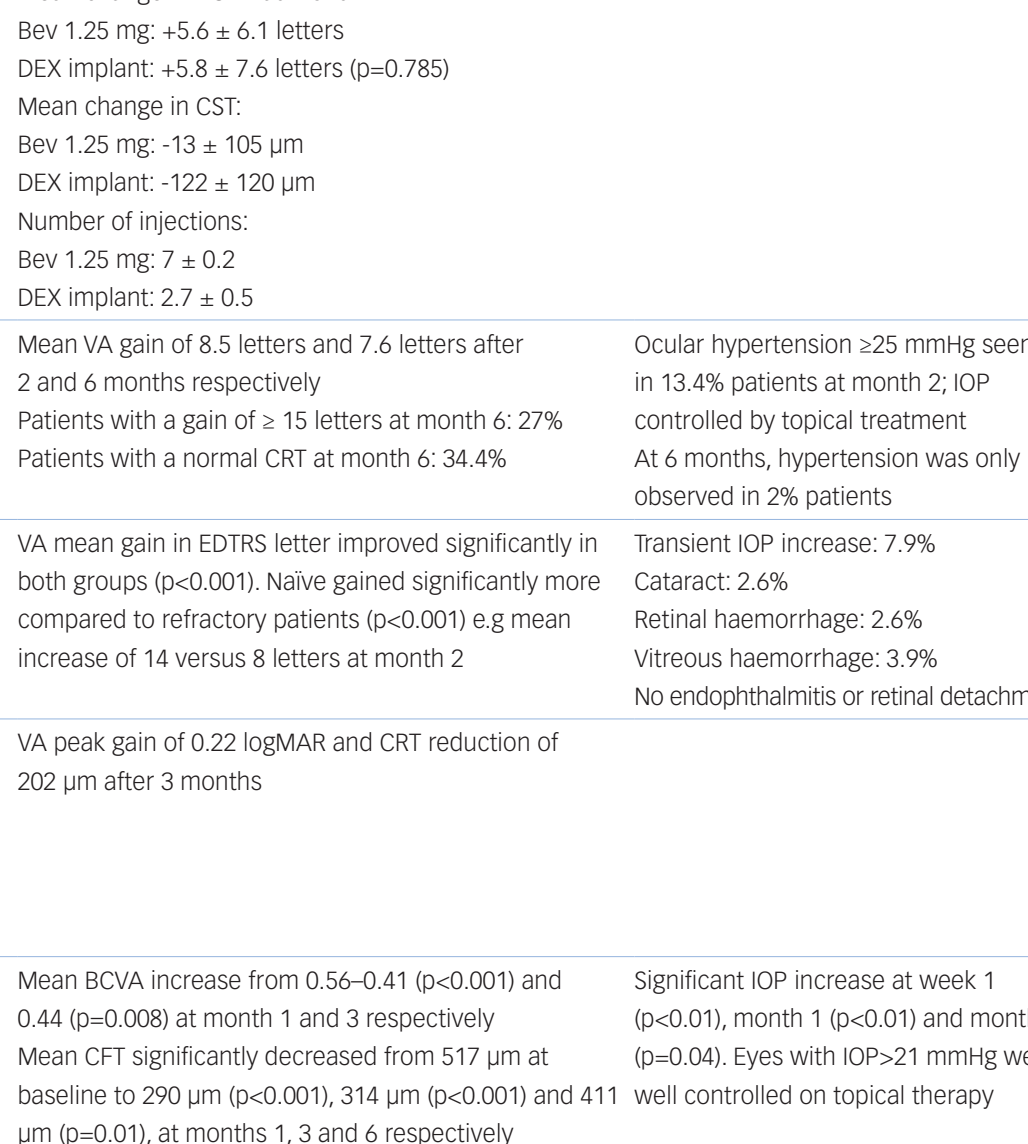

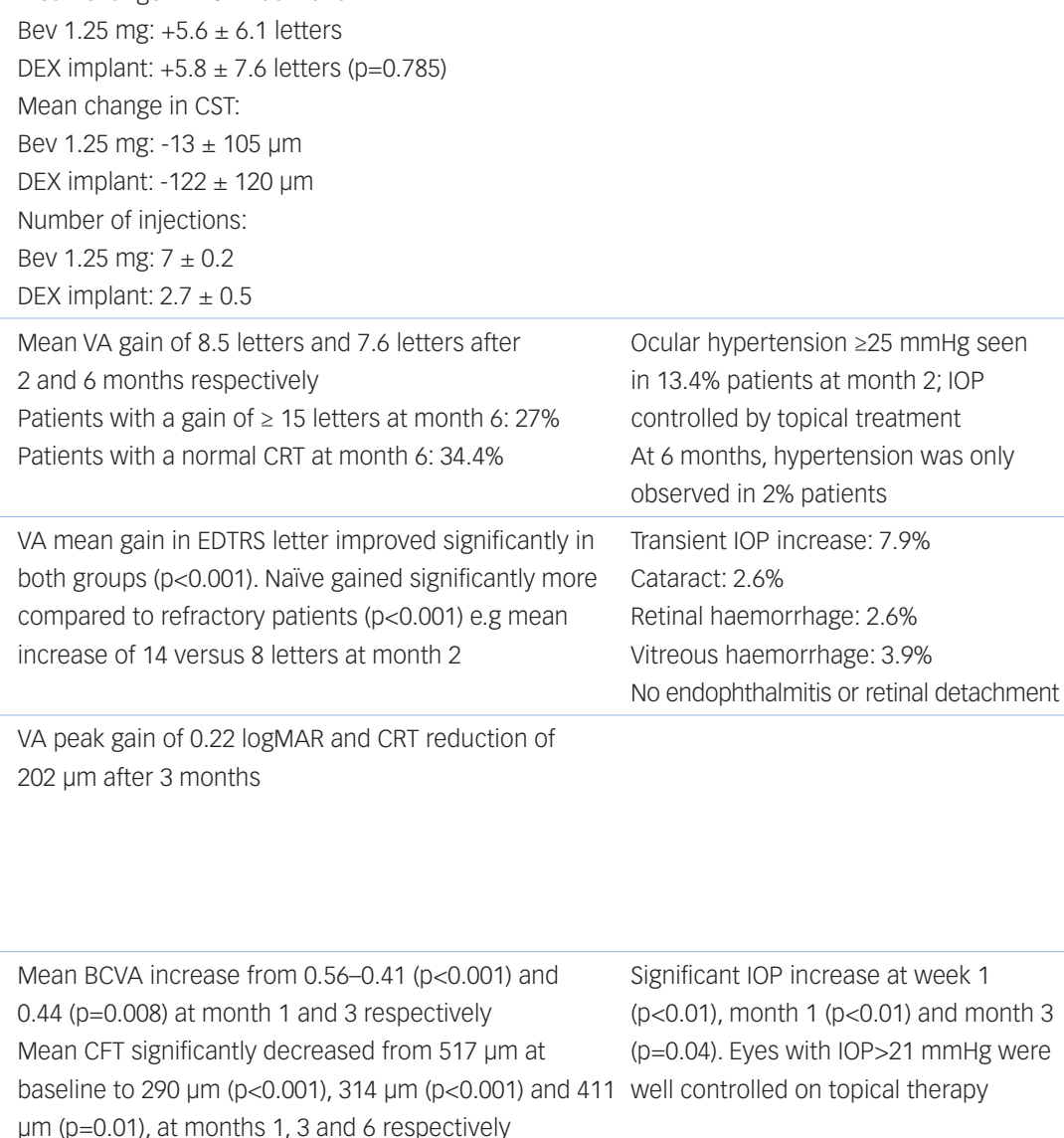

Dutra Medeiros et al. DEX implant $0.7 \mathrm{mg}$ (58 refractory

2014

Retrospective patients after laser or anti-VEGF treatment) Refractory: oedema of more than $250 \mu \mathrm{m}$ lasting at least 90 days after laser or anti VEGF treatment
Totan et al. 2015 Prospective

\section{DEX implant $0.7 \mathrm{mg}$ (30 refractory eyes, Mean BCVA increase from 0.56-0.41 ( $p<0.001)$ and} previously treated with Bev monthly for 3 months DME duration $\geq 6$ months

Lazic et al. 2014 Prospective

Snellen lines $(p=0.0038)$
DEX implant $0.7 \mathrm{mg}$ (15 refractory patients, previously treated unsuccessfully with bevacizumab)

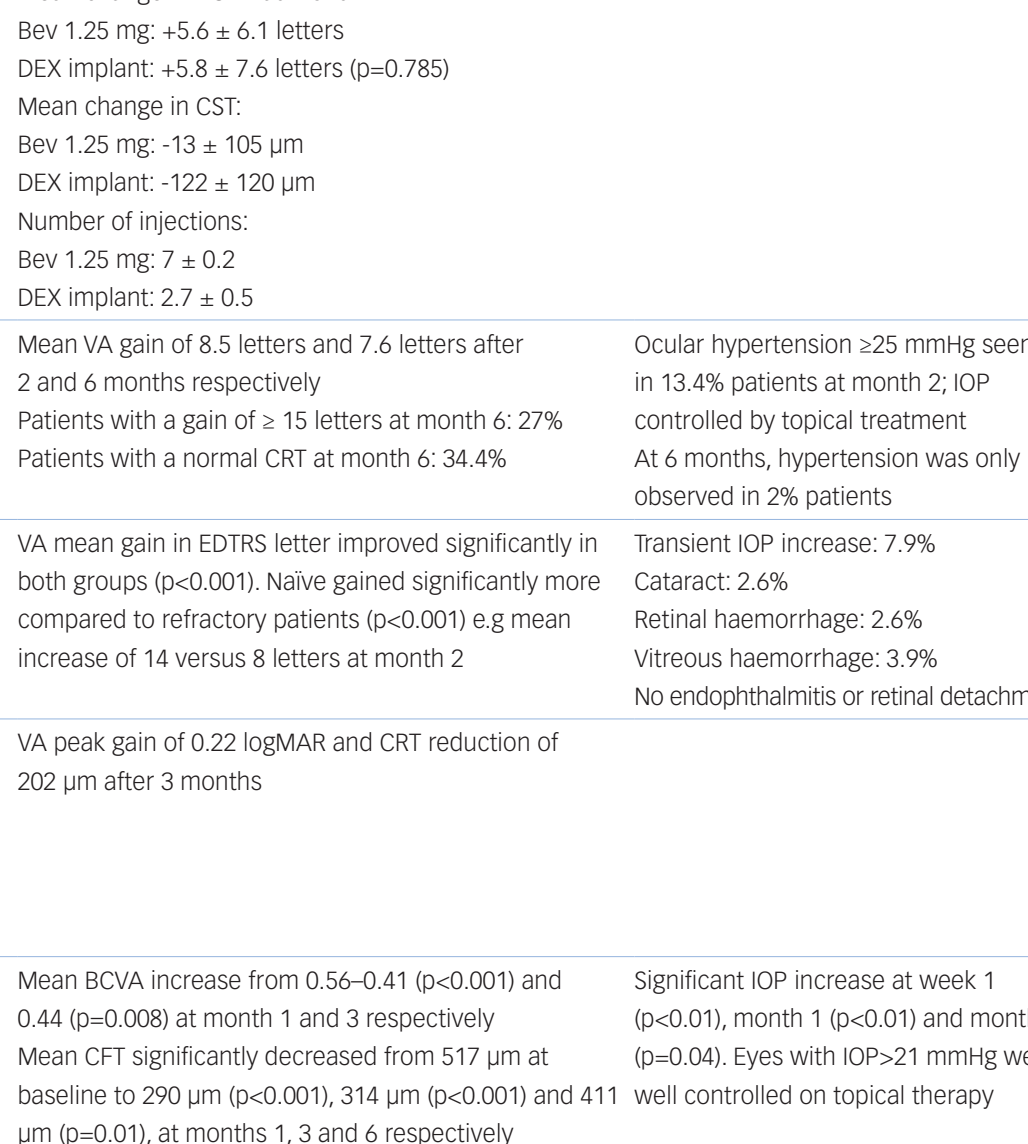

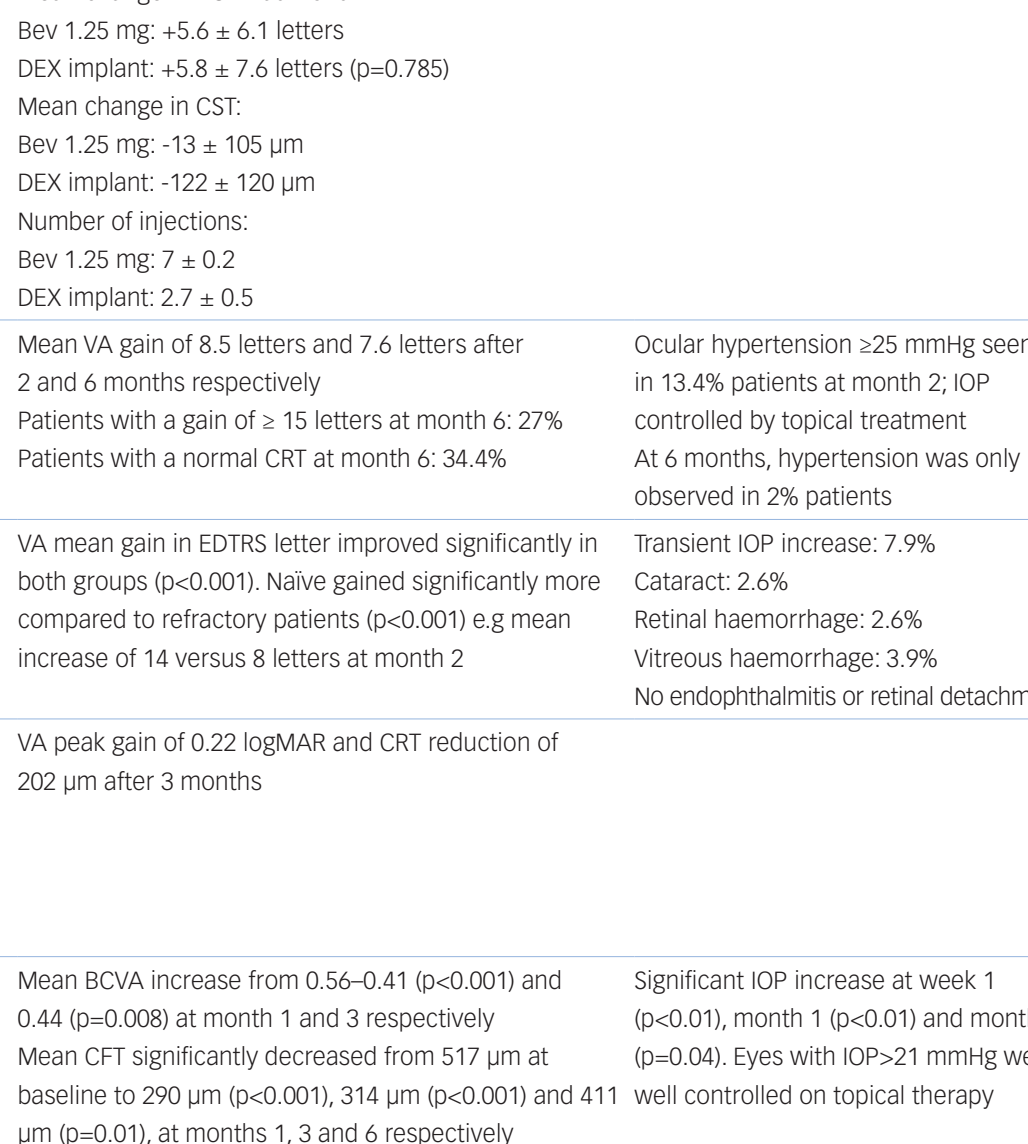

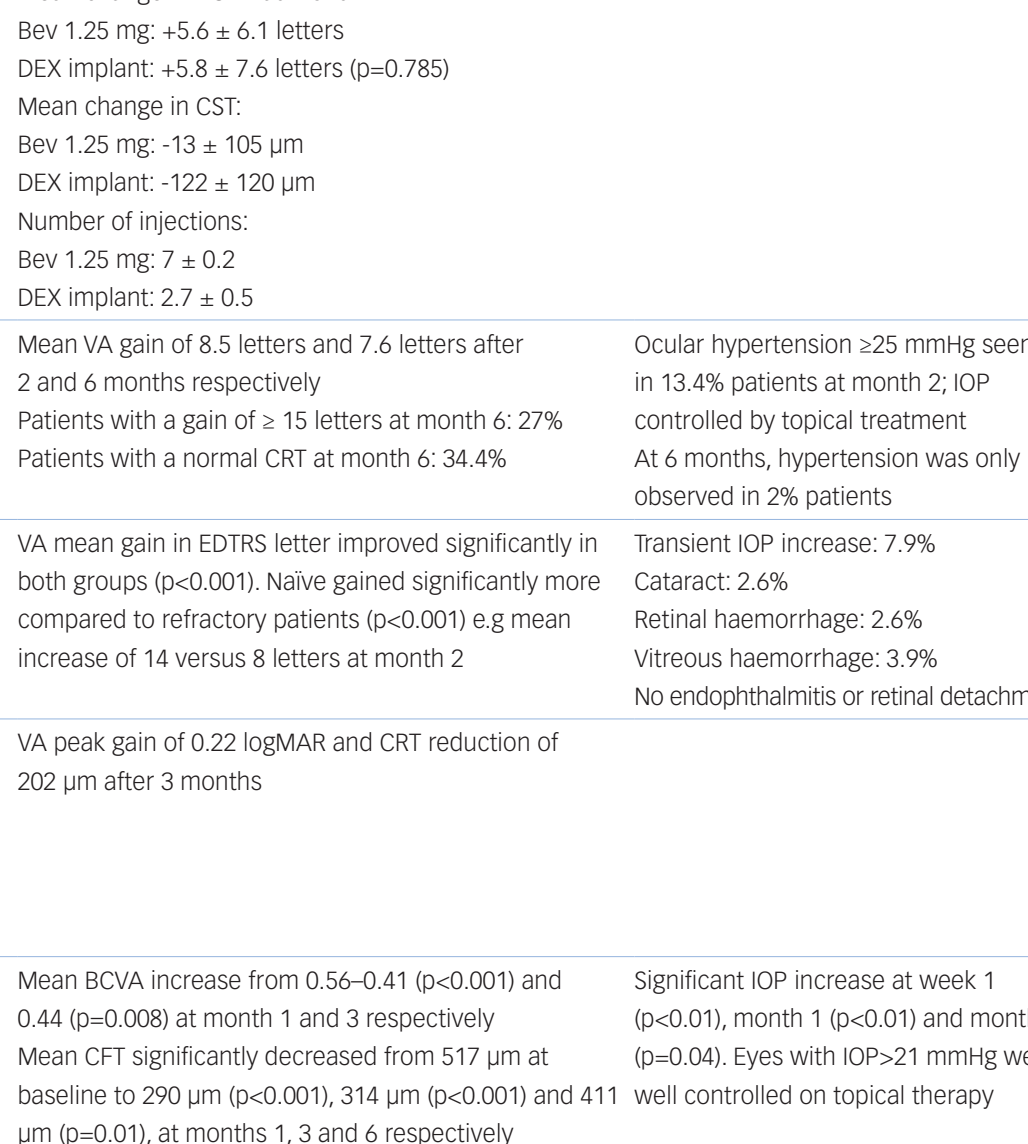

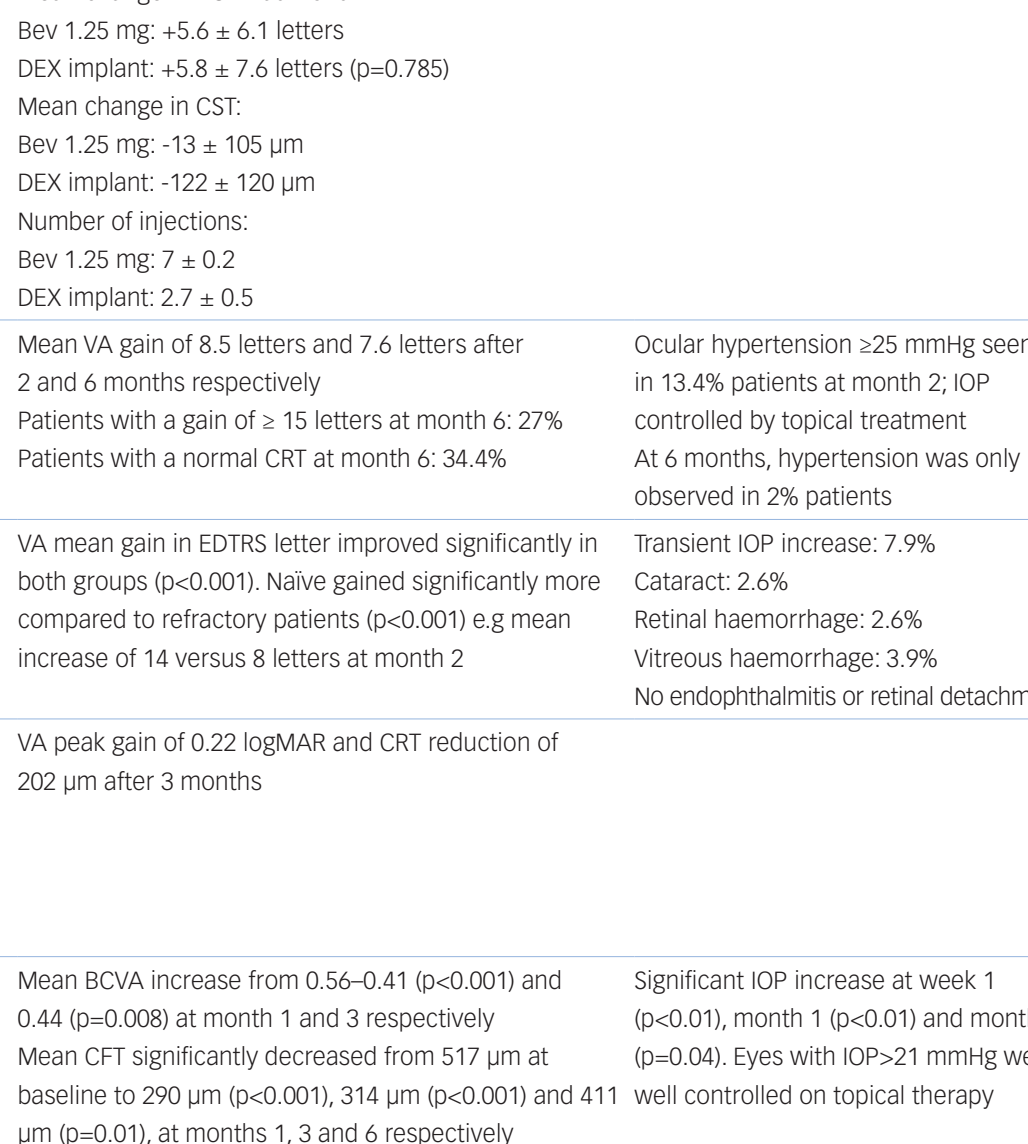

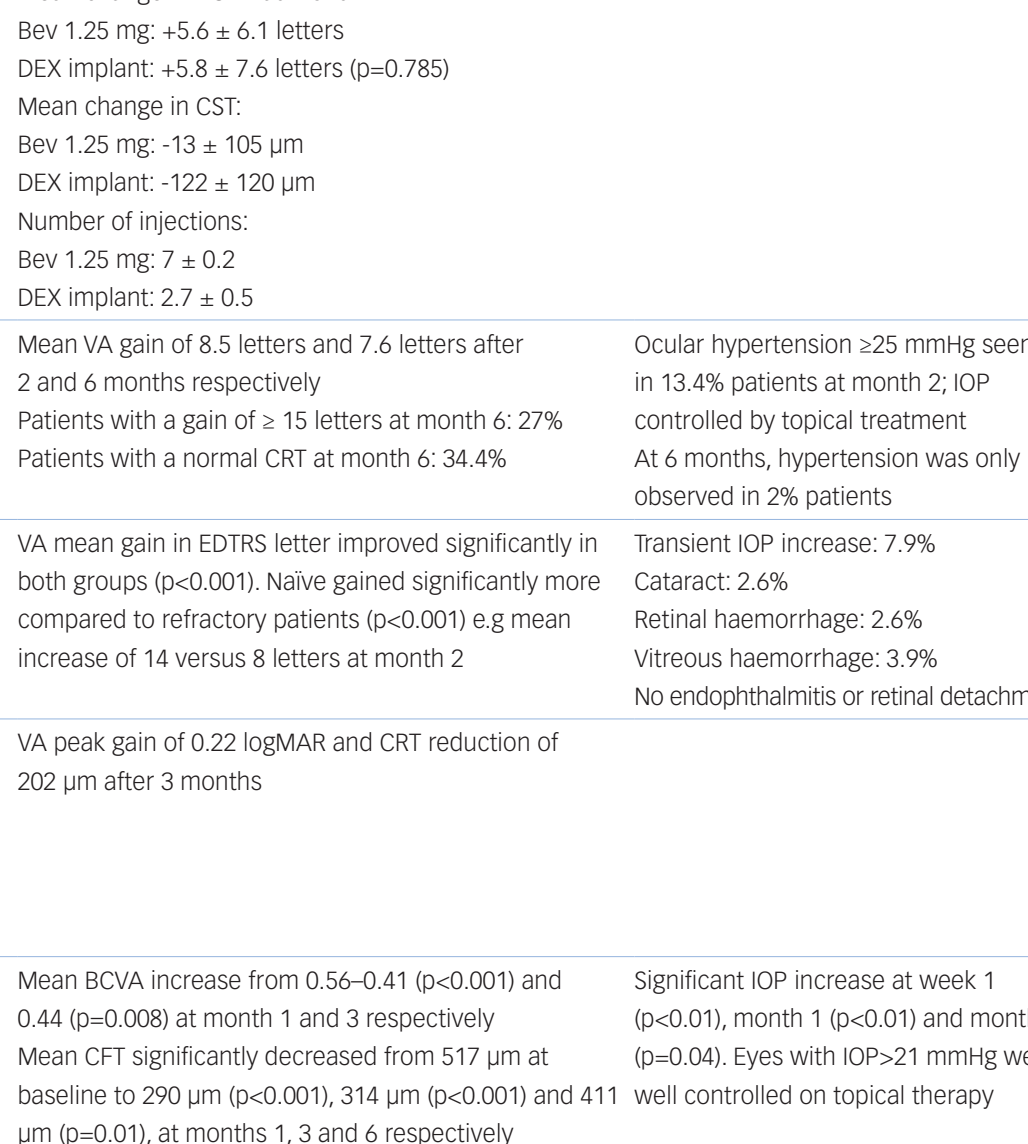

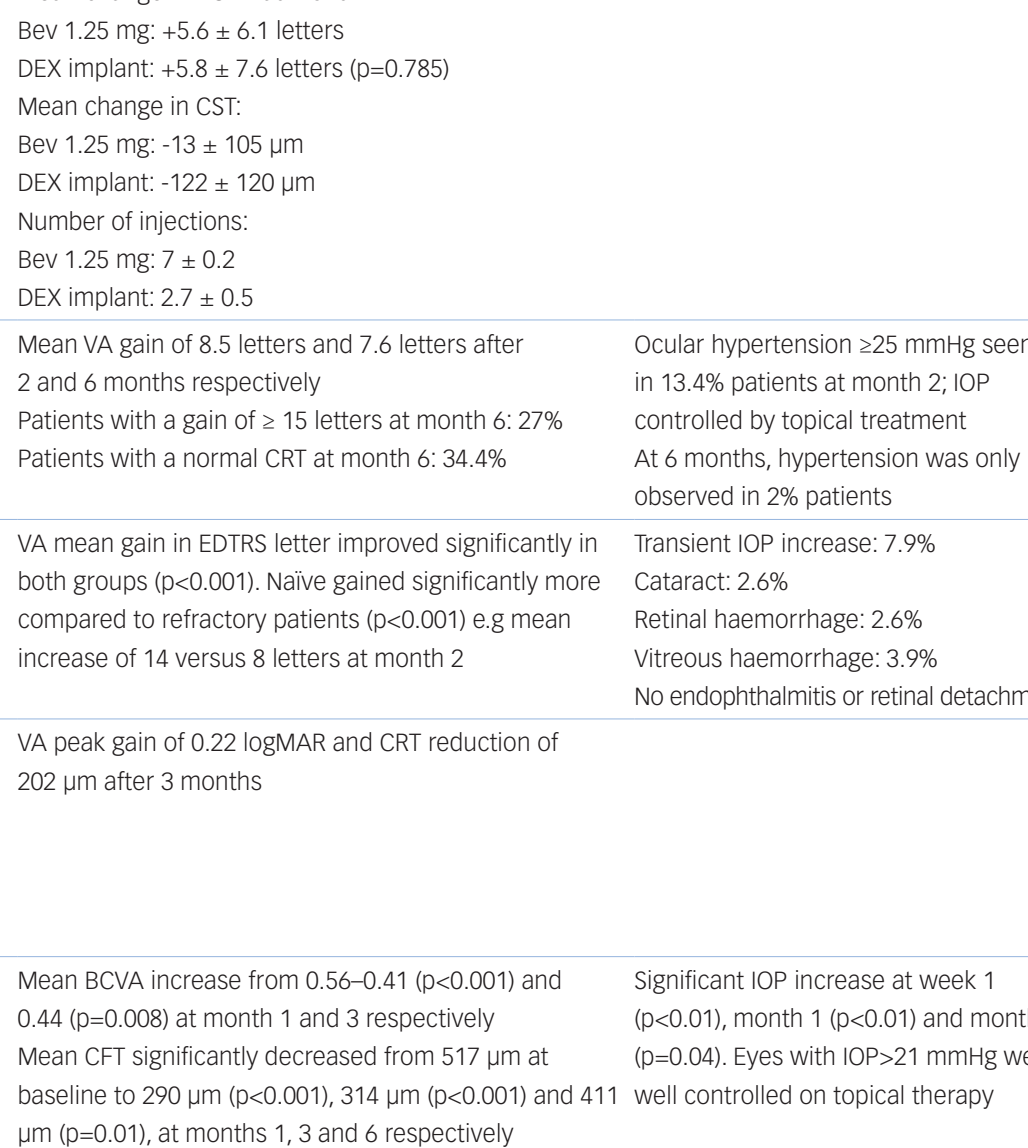

Mean CFT decreased from 462-346 $\mu \mathrm{m}(\mathrm{p}=0.0288)$

At month 6:

Similar findings in BCVA improvement and CFT reduction for both groups

Medeiros et al. 2014 DEX implant 0.7 mg (54 refractory

Retrospective patients; vitrectomized and non vitrectomized eyes)

\author{
.
}

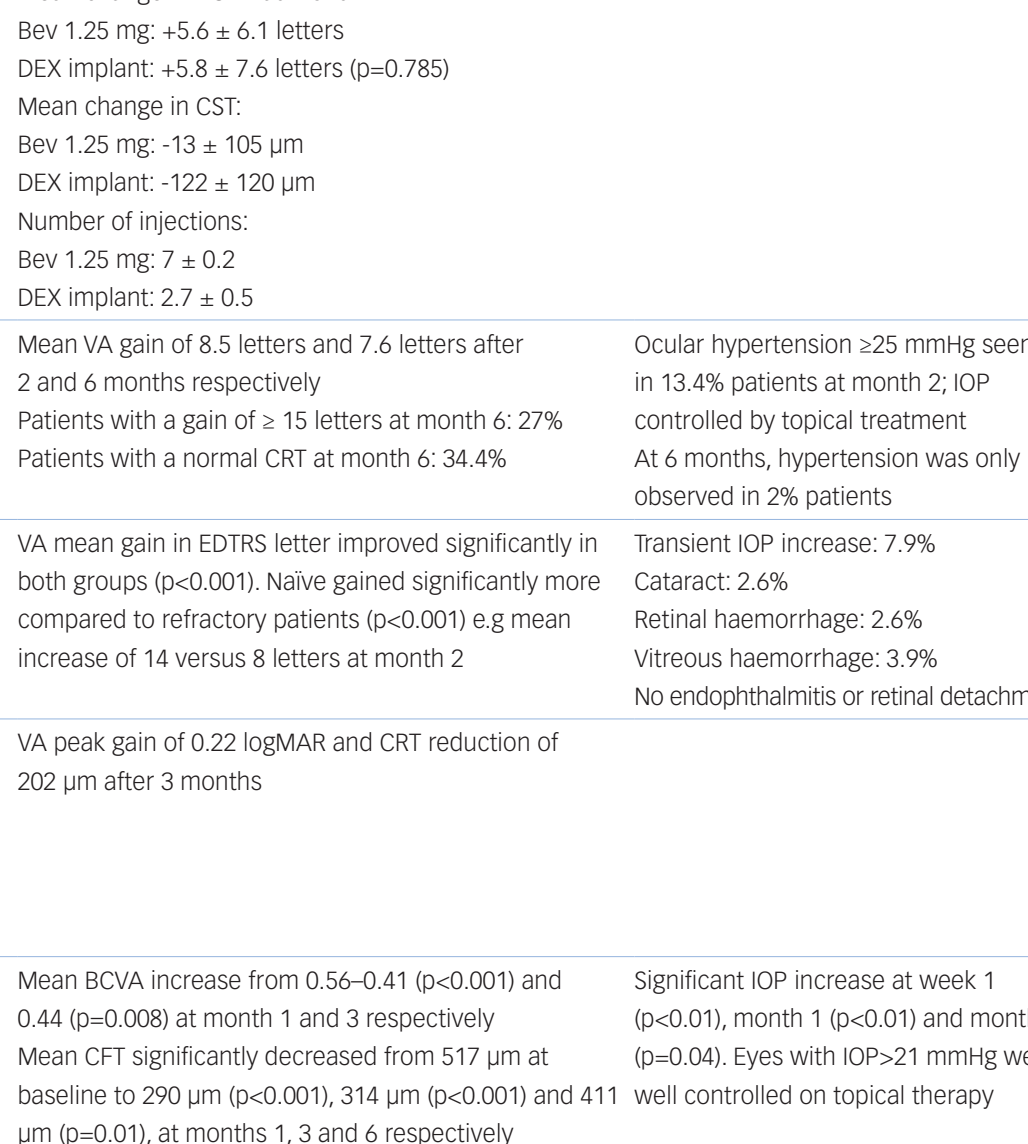

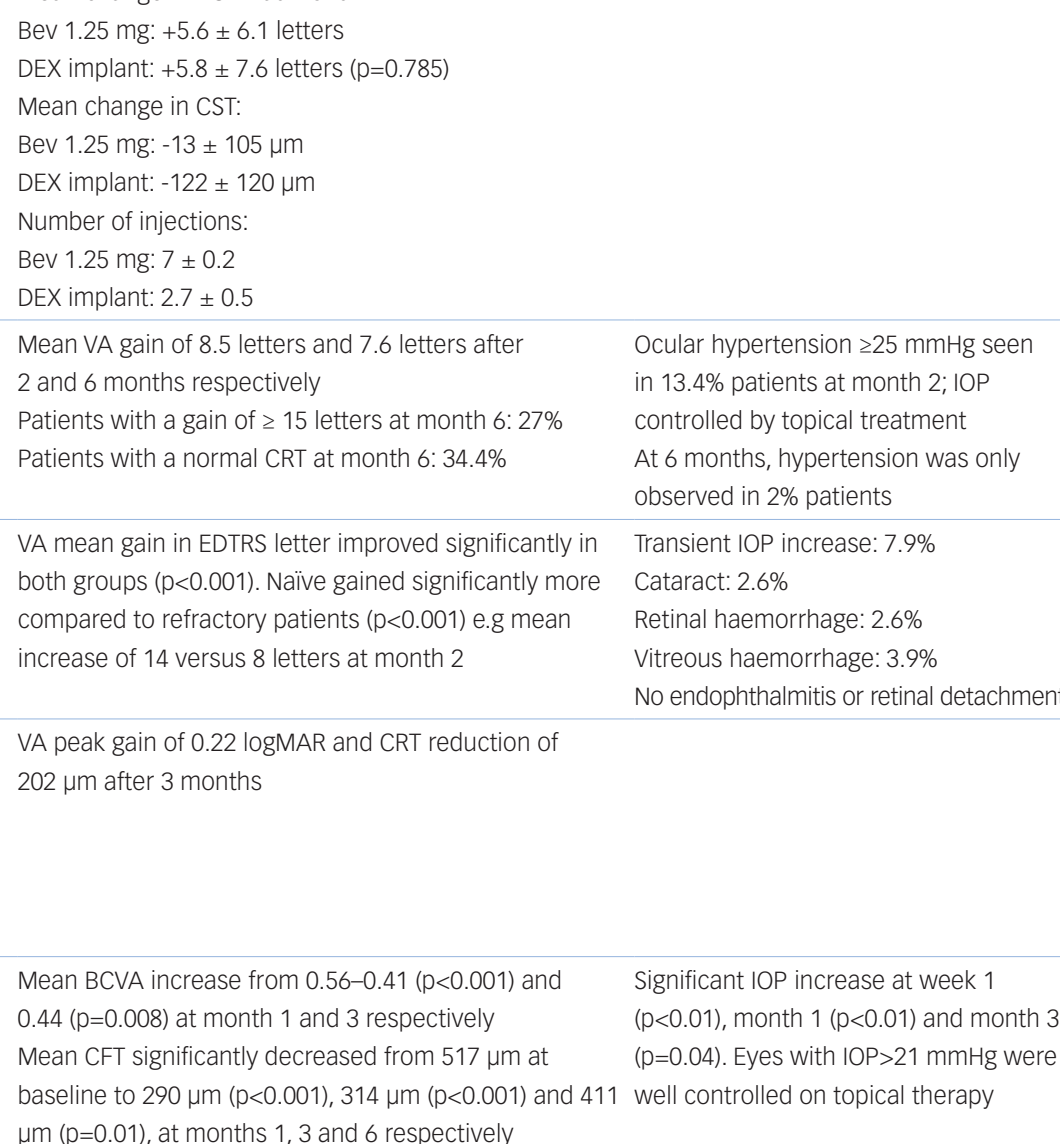

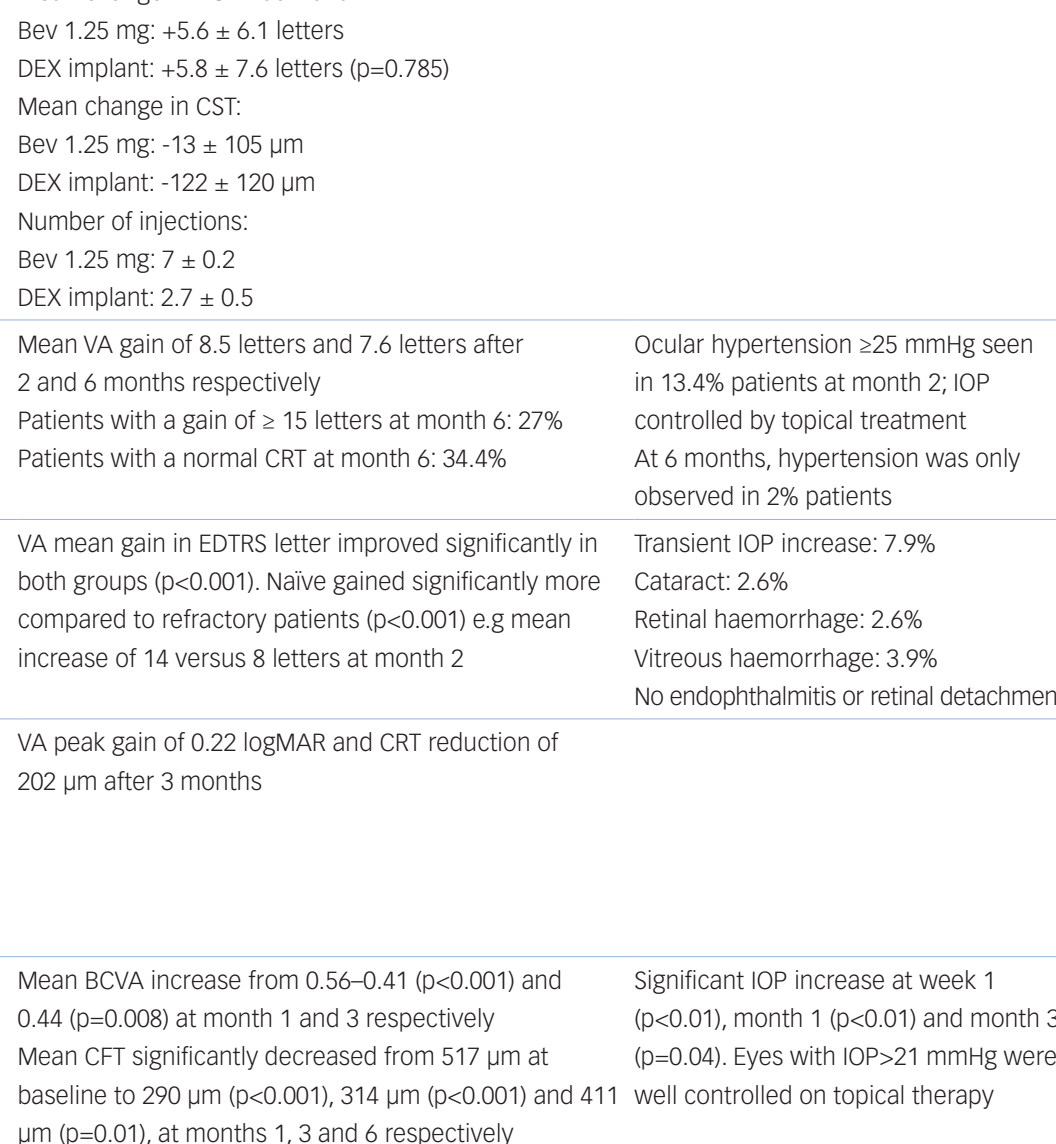

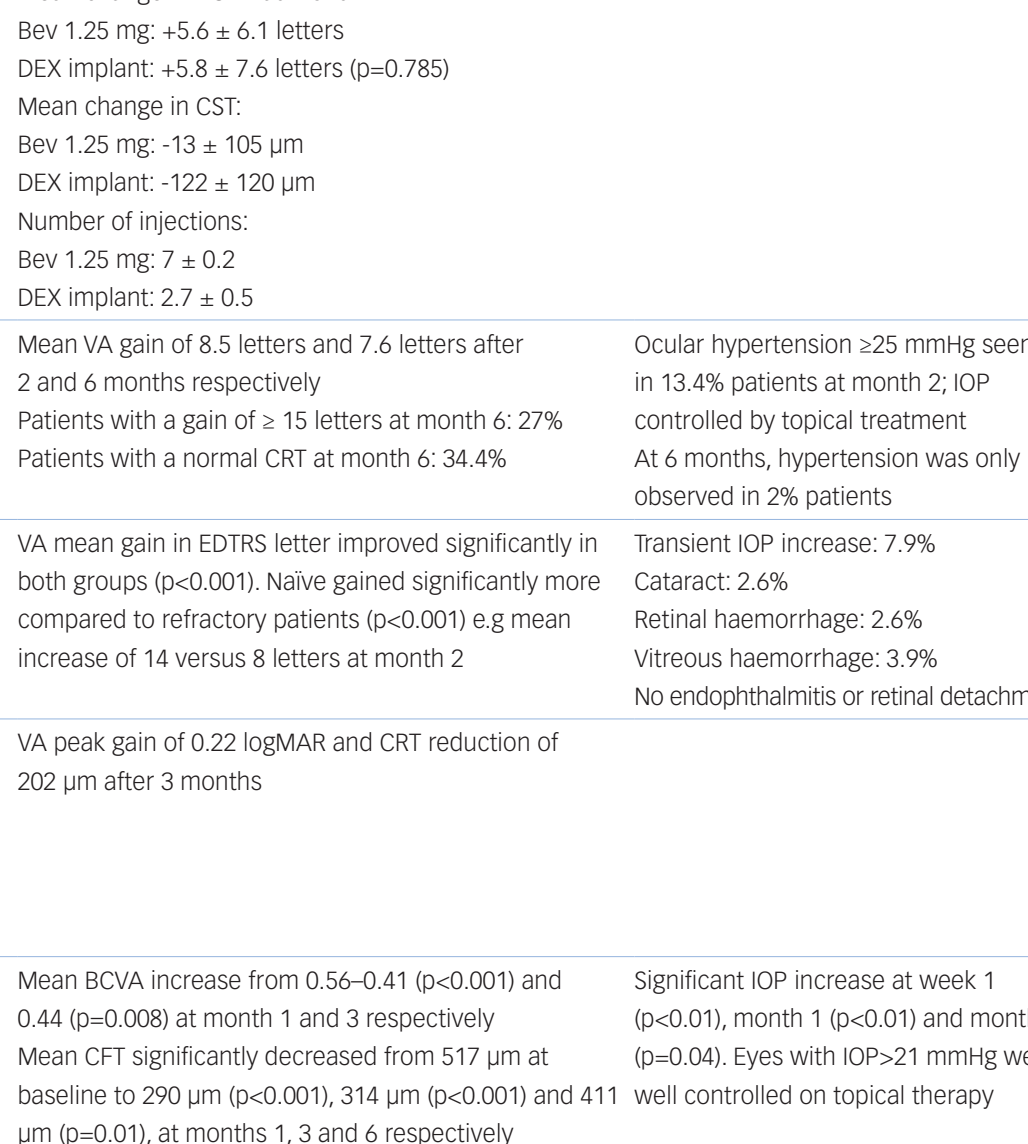

\begin{tabular}{|c|c|c|c|}
\hline $\begin{array}{l}\text { Dutra Medeiros et al. } \\
2014 \\
\text { Retrospective }\end{array}$ & $\begin{array}{l}\text { DEX implant } 0.7 \mathrm{mg} \text { ( } 58 \text { refractory } \\
\text { patients after laser or anti-VEGF } \\
\text { treatment) } \\
\text { Refractory: oedema of more than } \\
250 \mu \mathrm{m} \text { lasting at least } 90 \text { days after } \\
\text { laser or anti VEGF treatment }\end{array}$ & $\begin{array}{l}\text { VA peak gain of } 0.22 \text { logMAR and CRT reduction of } \\
202 \mu \mathrm{m} \text { after } 3 \text { months }\end{array}$ & \\
\hline $\begin{array}{l}\text { Totan et al. } 2015 \\
\text { Prospective }\end{array}$ & $\begin{array}{l}\text { DEX implant } 0.7 \mathrm{mg} \text { (30 refractory eyes, } \\
\text { previously treated with Bev monthly for } \\
3 \text { months } \\
\text { DME duration } \geq 6 \text { months }\end{array}$ & $\begin{array}{l}\text { Mean BCVA increase from } 0.56-0.41(p<0.001) \text { and } \\
0.44(p=0.008) \text { at month } 1 \text { and } 3 \text { respectively } \\
\text { Mean CFT significantly decreased from } 517 \mu \mathrm{m} \text { at } \\
\text { baseline to } 290 \mu \mathrm{m}(\mathrm{p}<0.001), 314 \mu \mathrm{m}(\mathrm{p}<0.001) \text { and } 411 \\
\mu \mathrm{m}(\mathrm{p}=0.01) \text {, at months } 1,3 \text { and } 6 \text { respectively }\end{array}$ & $\begin{array}{l}\text { Significant IOP increase at week } 1 \\
(p<0.01) \text {, month } 1(p<0.01) \text { and month } 3 \\
(p=0.04) \text {. Eyes with IOP }>21 \mathrm{mmHg} \text { were } \\
\text { well controlled on topical therapy }\end{array}$ \\
\hline $\begin{array}{l}\text { Lazic et al. } 2014 \\
\text { Prospective }\end{array}$ & $\begin{array}{l}\text { DEX implant } 0.7 \mathrm{mg} \text { ( } 15 \text { refractory } \\
\text { patients, previously treated } \\
\text { unsuccessfully with bevacizumab) }\end{array}$ & $\begin{array}{l}\text { Mean BCVA increase after } 2 \text { months from 0.29-0.39 } \\
\text { Snellen lines }(p=0.0038) \\
\text { Mean CFT decreased from } 462-346 \mu m(p=0.0288)\end{array}$ & \\
\hline $\begin{array}{l}\text { Medeiros et al. } 2014 \\
\text { Retrospective }\end{array}$ & $\begin{array}{l}\text { DEX implant } 0.7 \mathrm{mg} \text { (54 refractory } \\
\text { patients; vitrectomized and non } \\
\text { vitrectomized eyes) }\end{array}$ & $\begin{array}{l}\text { At month 6: } \\
\text { Similar findings in BCVA improvement and CFT } \\
\text { reduction for both groups }\end{array}$ & \\
\hline
\end{tabular}

BCVA = best corrected visual acuity; Bev = bevacizumab; CFT = central foveal thickness; $C R T=$ central retinal thickness; $C S T=$ central subfield thickness; DEX = dexamethasone; $D M E=$ diabetic macular oedema; $D R=$ diabetic retinopathy; EDTRS = early treatment diabetic retinopathy study; IOP = intraocular pressure; IOgMAR = LOgarithm of the Minimum Angle of Resolution; VA = visual acuity.

of ranibizumab. After three months, DEX implant showed a better efficacy (mean VA gain of 8.5 versus 4 letters). This significance was lost after six months (overall VA gain of 2.5 versus 2 letters). ${ }^{32} \mathrm{~A}$ prospective study comparing bevacizumab administered as monotherapy with the DEX implant in the treatment of persistent DME reported that both groups had similar VA gains, while patients in the DEX implant group achieved a significantly greater reduction of central subfield thickness (CST) compared with the bevacizumab group. ${ }^{33}$

The authors of a retrospective study reported DEX implant to be safe and effective over a mean treatment period of 9.8 months. The mean improvement in VA at six months was 7.6 letters. The mean re-injection interval was 5.4 months with on average. ${ }^{34} \mathrm{~A}$ prospective study on refractory and naïve DME patients treated with DEX implant and laser as needed reported a significant improvement in VA from baseline $(p<0.001)$ in both groups, especially in the naivve group. ${ }^{35}$

A retrospective study analysed data of refractory DME patients receiving a single DEX implant. The authors concluded that the DEX implant is effective in difficult-to-treat patients with long-standing oedema. ${ }^{36} \mathrm{~A}$ prospective study in patients unsuccessfully pre-treated with bevacizumab demonstrated that DEX implant significantly increased mean BCVA (logMAR) at one and three months. IOP increases were well controlled with topical anti-glaucoma monotherapy. ${ }^{37}$ Similar efficacy was reported by Lazic et al. from a prospective dataset in the same patient type. ${ }^{38}$ 
Figure 1: Injection frequency for ranibizumab

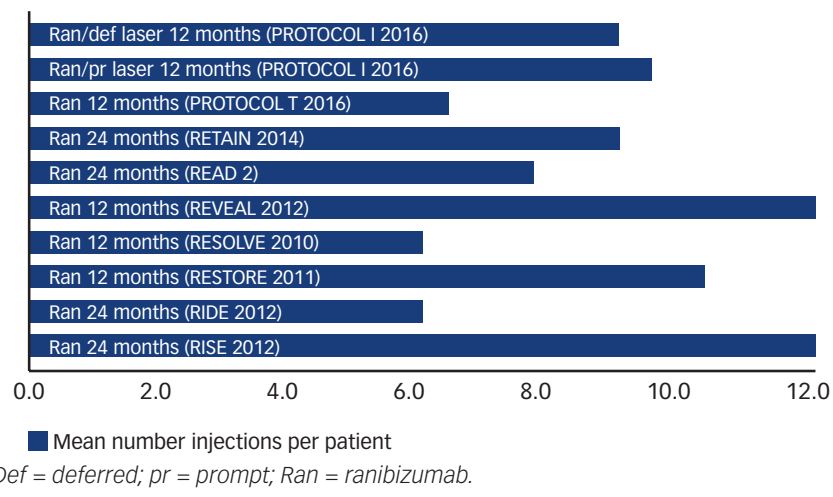

A retrospective comparison over six months in vitrectomised versus non-vitrectomised patients with refractory DME reported similar BCVA improvements and reduction of central foveal thickness (CFT) in both groups. ${ }^{39}$

\section{Discussion}

Based on the existing data, VEGF inhibitors as well as corticosteroids have demonstrated efficacy and safety in DME. Furthermore, the use of intravitreal drug delivery in combination with mechanical approaches such as laser therapy show promise for improving visual outcomes and decreasing the need for re-treatment. ${ }^{40}$

VEGF inhibitors are easy to apply and used as treatment of first choice. Based on the recent PROTOCOL T findings, aflibercept seems to achieve better outcomes in eyes with worse baseline VA. An obvious drawback is the high frequency of injection. However, some longer-term data suggest that this frequency is reduced overtime, while still maintaining VA gains previously achieved. Overall, real-world outcomes data do not suggest a lower treatment frequency, if similar efficacy results want to be obtained (Figures 1, 2 and 3).

However, frequent injections increase the number of treatment-related AEs. Furthermore, they put a great burden on the patient suffering from this chronic disease and decrease patient compliance. Delivery systems can lead to a reduction of these disadvantages. ${ }^{41}$

Available delivery systems are so far loaded only with corticosteroids. The non-biodegradable delivery system releasing FAc is only available as a last resort option in very restricted patient populations (chronic patients who are resistant to other treatments), with little real-world data currently available. Reasons for this include the long-term nature of the therapy, a potential need to remove the empty device and concerns about lesser control of emerging side effects.

In contrast, DEX implant is indicated in all types of DME for pseudophakic patients or in patients, where alternative treatments are not effective or are inappropriate. The biodegradable implant is injected and does not need to be removed. Compared with anti-VEGF injections, it needs to be administered less often. A fair amount of shorter-term clinical practice data has started to emerge, reporting that treatment intervals remain the same or are slightly shorter or longer. Results suggest a similar to better efficacy compared with the phase III data clinical trial data, and similar efficacy to anti-VEGF. Additional findings suggest that improvement of macular morphology with the DEX implant could be more pronounced. Furthermore,

\section{Figure 2: Injection frequency for bevacizumab}

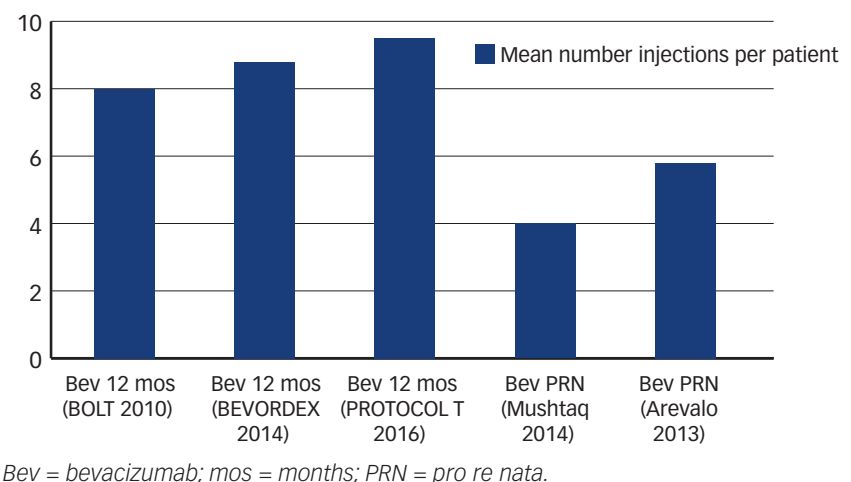

Bev $=$ bevacizumab; mos $=$ months; $P R N=$ pro re nata.

\section{Figure 3: Injection frequency for aflibercept}

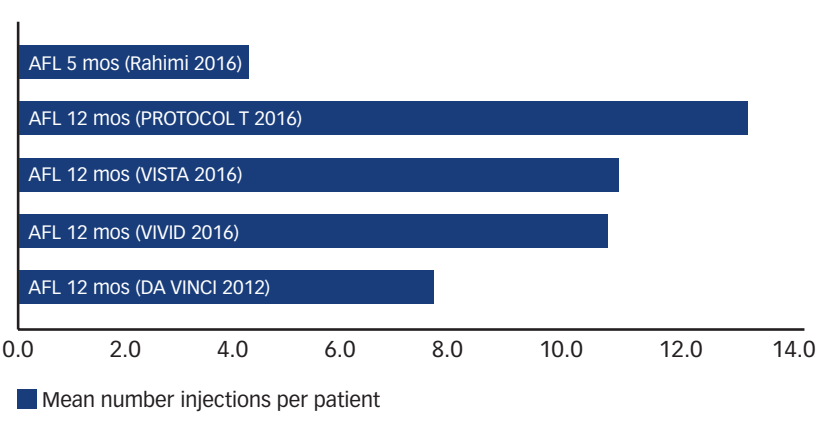

$A F L=$ aflibercept; $m o s=$ months.

\section{Figure 4: Injection frequency for dexamethasone implant}

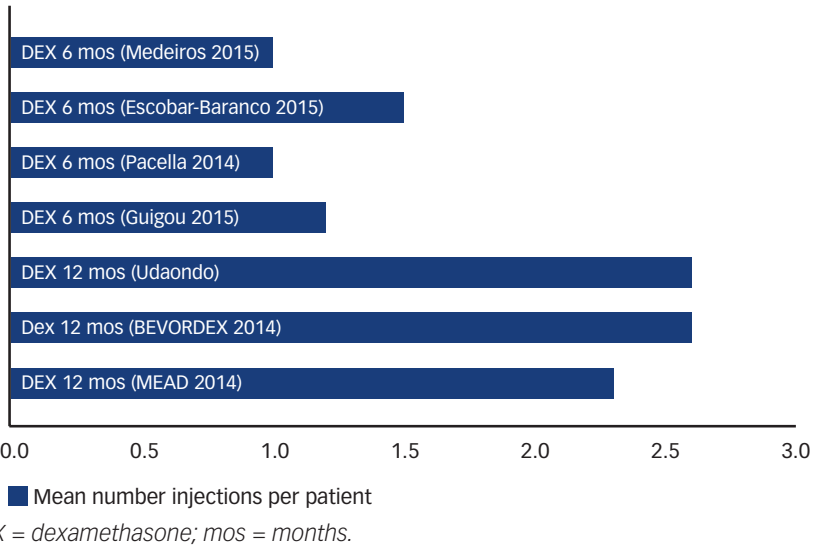

data on combining the DEX implant with anti-VEGF compounds is also emerging.

Major limitations to comparing pivotal trials with clinical practice data are the differing, mostly shorter study periods, different reporting of efficacy endpoints such as VA, smaller patient numbers and less clearly defined patient populations, especially in respect to duration of DME. Based on the pivotal trial findings, the current assumptions should be that delayed treatment of patients results in lower overall vision gains.

Apart from injection-related ocular AEs, side-effect profiles between VEGF inhibitors and corticosteroids differ. Main concerns for the latter group revolve around the significant progression of cataract and an 
increase of IOP. Even though rise of IOP has also been reported in antiVEGF compounds, this is to a much lesser extent.

A growing concern with intravitreal ranibizumab use in other retinal diseases (such as age-related macular degeneration) is the possible increased risk of occurrence and increased growth of geographic atrophy. Intravitreally applied corticosteroids at low doses have not been observed to exert relevant retinal toxicity. ${ }^{36}$

Systemic AEs in general are not associated with corticosteroids, but rather with VEGF inhibitors. There are no consistent reports so far. Nonocular serious AEs (myocardial infarction, stroke and death) have been reported for ranibizumab in a slightly higher incidence in the treatment than the sham group in studies for DME and other retinal diseases (e.g., $2.5 \%$ versus $0.8 \%$ in the MARINA study). Cerebrovascular accidents occurred in $4 \%$ of ranibizumab $0.5 \mathrm{mg}$ patients in RISE and $2.4 \%$ of ranibizumab $0.5 \mathrm{mg}$ patients in RIDE. Reported rates of AEs differed amongst studies and groups. However, studies were not powered to detect small differences in rates of infrequent events.? The authors of a recent study comparing outcomes of all VEGF inhibitors in DME propose that due to higher APTC event rates found in ranibizumab, that such events should also be monitored in future. ${ }^{12} \mathrm{~A}$ recent systematic review and meta-analysis of prolonged monthly anti-VEGF use in DME, the assessment of the highest-level exposure group (patients receiving monthly treatment over two years) revealed a possibly increased risk for death and potentially for cerebrovascular accidents. Therefore, the authors concluded that total exposure to anti-VEGF drugs in patients at high risk for vascular diseases should be taken into consideration.42

\section{Conclusions}

Management of DME is complex and often multiple treatment approaches are needed. Emerging data on the newly licensed therapies show VEGF inhibitors and corticosteroids to be equally effective. Corticosteroids appear to be a less treatment-intensive alternative compared with anti-VEGF treatment in DME. While corticosteroids have a widely known safety profile and are already used in well-defined patient populations, recent safety findings on anti-VEGF treatments suggest that there is a need to select patients more carefully.

Currently available datasets scarcely allow direct comparison due to different reporting formats for efficacy and safety parameters, as well as diverging reporting periods. Future real-world data will need to be generated over longer periods of time to inform about longterm treatment efficacy, ideally using uniform reporting parameters to facilitate better comparison of data sets for the same treatment, as well as between treatments.

Future-generation devices should allow even longer release durations and increased target specificity to prolong their action, minimise side effects and achieve patient compliance.
1. Holman N, Forouhi NG, Goyder E, et al., The Association of Public Health Observatories (APHO) Diabetes Prevalence Model: estimates of total diabetes prevalence for England 2010-2030, Diabet Med, 2011;28:575-82.

2. Wong TY, Mwamburi M, Klein R, et al., Rates of progression in diabetic retinopathy during different time periods: a systematic review and meta-analysis, Diabetes Care 2009:32:2307-13.

3. Narayan KM, Boyle JP, Geiss LS, et al., Impact of recent increase in incidence of future diabetes burden, Diabetes Care, 2006;29:2114-16

4. Early Treatment Diabetic Retinopathy Study Research Group, Photocoagulation for diabetic macular edema: early treatment diabetic retinopathy study report number 1 , Arch Ophthalmol, 1985;103:1796-806.

5. Massin PG, Ranibizumab in diabetic macular edema, Joint Meeting of the American Academy Ophthalmology and European Society of Ophthalmology, November $8-112008$ Atlanta, Georgia.

6. Brown DM, Nguyen $\mathrm{QD}$, Marcus DM, et al., Long-term outcomes of ranibizumab therapy for diabetic macular edema: the 36-month results from two phase II trials: RISE and RIDE, Ophthalmology, 2013:120:2013-22.

7. Ford JA, Lois N, Royle P et al., Current treatment in diabetic macular oedema: systematic review and meta-analysis, $B M J$ Open, 2013;3:e002269. Doi:10.1136/bmjopen-2012-002269

8. Schmidt-Erfurth U, Lang GE, Holz FG, et al., Three-year outcomes of individualized ranibizumab treatment in patients with diabetic macular edema, the RESTORE extension study, Ophthalmology, 2014;121:1045-53.

9. Googe J, Brucker AJ, Bressler NM, et al., Randomized tria evaluating short-term effects of intravitreal ranibizumab or triamcinolone acetonide on macular edema after focal/ grid laser for diabetic macular edema in eyes also receiving panretinal photocoagulation, Retina, 2011;31:1009-27.

10. Elman MJ, Ayala A, Bressler NM, et al., Intravitreal Ranibizumab for diabetic macular edema with promt versus Ranibizumab for diabetic macular edema with promt versus
deferred laser treatment. 5 year randomized trial results, Ophthalmology, 2015:122:375-81.

11. Bressler SB, Glassman AR, Almukhtar T, et al., Five-year outcomes of ranibizumab with prompt or deferred laser versus laser or triamcinolone plus deferred ranibizumab for diabetic macular edema, Am J Ophthalmol, 2016;164:57-68.

12. Menchini U, Bandello F, De Angelis V , et al., Ranibizumab for visual impairment due to diabetic macular edema: real-world evidence in the Italian population (PRIDE Study) J Ophthal, 2015;324841.

13. Wells JA, Glassman AR, Ayala AR, et al., Aflibercept, bevacizumab, or ranibizumab for diabetic macular edema: two year results from a comparative effectiveness randomized clinical trial, Ophthalmology, 2016;123:1351-9.

14. Michaelidis M, Kaines A, Hamilton RD, et al., A Prospective Randomized Trial of Intravitreal Bevacizumab or Laser Therapy in the Management of Diabetic Macular Edema (BOL Study), Ophthalmology, 2010;117:1078-86.

Study), Ophthalmology, 2010;117:1078-86.
5. Faghihi H, Roohipoor R, Mohammadi SF, et al., Intravitreal bevacizumab versus combined bevacizumab-triamcinolone versus macular laser photocoagulation in diabetic macular edema, Eur J Ophthalmol, 2008;18:941-8.

16. Lam DS, Lay TY, Lee VY, et al., Efficacy of 1.25 MG versus 2.5 MG intravitre ix-month results of a randomized controlled tial, Retina six-month results of a randomized controlled trial, Retina,

17. Ahmadieh $\mathrm{H}$, Ramezani $\mathrm{A}$, Shoeibi $\mathrm{N}$, et al., Intravitreal bevacizumab with or without triamcinolone for refractory diabetic macular edema; a placebo-controlled randomized clinical trial, Graefes Arch Clin Exp Ophthalmol 2008;246:483-9.

18. Do DV, Nguyen QD, Boyer D, et al., One year outcomes in the DA VINCI study of VEGF Trap-Eye in eyes with diabetic macular edema, Ophthalmology, 2012;119:1658-65.

19. Brown DM, Schmidt-Erfurth U, Do DV, et al, Intravitrea Aflibercept for Diabetic Macular Edema: 100-Week Results From the VISTA and VIVID Studies, Ophthalmology, 2015;122:2044-52

20. Rahimy E, Shahlaee E, Khan MA, Conversion to aflibercept for persistent DME resulted in significant anatomic improvements. While trends towards improved visua acuity and reduction in IOP were observed, these were not statistically significant, Am I Ophthalmol, 2016;164:118-27.

21. Campochiaro PA, Brown DM, Pearson A, et al., Sustained delivery of fluocinolone acetonidevitreous inserts provide benefit for at least 3 years in patients with diabetic macular edema, Ophthalmology, 2012;119:2125-32.

22. Cunha-Vaz J, Ashton P, lezzi R, et al., Sustained Delivery Fluocinolone Acetonide Vitreous Implants. Long-Term Benefit in Patients with Chronic Diabetic Macular Edema, Ophthalmology, 2014;121:1892-903.

23. Elaraoud I, Attawan A, Quhill F, Case Series Investigating the Efficacy and Safety of Bilateral Fluocinolone Acetonide (ILUVIEN) in Patients with Diabetic Macular Edema, Ophthalmol Ther, 2016; Feb 17. [Epub ahead of print]

24. Callanan DG, Gupta S, Boyer DS, et al., Dexamethasone intravitreal implant in combination with laser photocoagulation for the treatment of diffuse diabetic macular edema, Ophthalmology, 2013;120:1843-50.

25. Boyer DS, Faber D, Gupta S, et al., Dexamethasone intravitrea implant for the treatment of diabetic macular edema in vitrectomized patients, Retina, 2011;31:915-23.

26. Boyer DS, Yoon HY, Belfort R, et al., Three-year, randomized, sham-controlled trial of dexamethasone intravitreal implant in patients with diabetic macular edema, Ophthalmol, 2014;121:1904-14.

27. Augustin AJ, Kuppermann BD, Lanzetta $\mathrm{P}$, et al, Dexamethasone intravitreal implant in previously treated patients with diabetic macular edema: subgroup analysis of the MEAD study, BMC Ophthalmology, 2015;15:150.

28. Gillies MC, Lim L Campain A, et al, A randomized clinical trial of intravitreal bevacizumab versus intravitreal dexamethasone for diabetic macular edema: the BEVORDEX study, Ophthalmol, 2014:121:2473-81.

29. Fraser-Bell S, Lyndell LL, Campain A, et al., Bevacizumab or dexamethasone implants for DME: 2 year results (the Bevordex Study), Ophthalmology, 2016;123:1399-401.

30. Maturi RK, Bleau L, Saunders J, et al., A 112-month, single masked, randomized controlled study of eyes with persistent diabetic macular edema after multiple anti-VEGF injections to assess the efficacy of the dexamethasone-delayed to assess the efficacy of the dexamethasone-delayed delivery system as an adjunct to bevacizumab compar with continued bevaci

31. Pacella E, La Torre G, Turchetti P, et al., Evaluation of efficacy dexamethasone intravitreal implant compared to treatment with anti-VEGF in the treatment of diabetic macular edema, Senses Sci, 2014;1:164-8.

32. Shah SU, Harless A, Bleau L, Maturi K, Prospective randomized subject-masked study of intravitreal bevacizuman monotherapy versus dexamethasone implant monotherapy in the treatment of persistent diabetic macular edema, Retina, 2016 (Epub ahead of print; PMID 27124881).

33. Guigou S, Pommier S, Meyer F, et al., Efficacy and Safety of Intravitreal Dexamethasone Implant in Patients with Diabetic Macular Edema, Ophthalmologica, 2015;233:169-75.

34. Escobar-Barranco IJ, Pina-Marin B, Fernandez-Bonet $\mathrm{M}$, Dexamethasone Implants in Patients with Naïve or Refractory Diffuse Diabetic Macular Edema, Ophthalmologica, 2015;233:176-85

35. Dutra Medeiros M, Postorino M, Navarro R, et al , Dexamethasone intravitreal implant for treatment of patients with persistent diabetic macular edema, Ophthalmologica, 2014; 231:141-6

36. Totan Y, Güler E, Güragac FB, Dexamethasone Intravitrea implant for chronic diabetic macular edema resistant to intravitreal bevacizumab treatment, Curr Eye Res, 2015;22:1-7.

37. Lazic R, Lukic M, Boras I, et al., Treatment of anti-vascula endothelial growth-factor resistant diabetic macular edema with dexamethasone intravitreal implant, Retina, 2014:34:719-24.

38. Medeiros MD, Alkabes $M$, Navarro $R$, et al, Dexamethasone intravitreal implant in vitrectomized versus nonvitrectomized eyes for treatment of patient with persistent diabetic macula edema, J Ocul Pharmacol Ther, 2014;30:709-16.

39. The Diabetic Retinopathy Clinical Research Network, Randomized trial evaluating ranibizumab plus prompt or deferred laser or deferred laser or triamcinolone plus prompt laser for diabetic macular edema, Ophthalmology, 2010;117:1064-77.

40. Penha FM, Rodrigues EB, Maia M, et al., Retinal and ocular toxicity in occular application of drugs and chemicals - Part II: Retinal toxicity of current and new drugs, Ophthalmic Res, 2010;44:205-24.

41. Avery RL, Gordon GM, Systemic safety of prolonged monthly anti-vascular endothelial growth factor therapy for diabetic macular edema. A systematic review and meta-analysis, IAMA Ophthalmol, 2016:134:21-9.

42. Kuno N, Fujii S, Biodegradable Intraocular therapies for Retinal Disorders, Drugs Aging, 2010;27:117-34 